\title{
Rhabdochona angusticaudata sp. n. (Nematoda: Rhabdochonidae) from the Japanese eel Anguilla japonica, and new records of some other nematodes from inland fishes in Japan
}

\author{
František Moravec $^{1}$ and Kazuya Nagasawa ${ }^{2}$
}

${ }^{1}$ Institute of Parasitology, Biology Centre of the Czech Academy of Sciences, Branišovská 31, 3705 České Budějovice, Czech Republic;

${ }^{2}$ Graduate School of Biosphere Science, Hiroshima University, 1-4-4 Kagamiyama, Higashi-Hiroshima 739-8528, Japan

\begin{abstract}
Collections of parasitic nematodes of fishes from some freshwater and brackish-water localities in Honshu, Shikoku and Hokkaido, Japan, carried out in 1996-2009, yielded the following eight species: Hysterothylacium haze (Machida, Takahashi et Masuuchi, 1978) (Anisakidae), Paraquimperia sp., Pingus sinensis Hsü, 1933 (both Quimperiidae), Heliconema anguillae Yamaguti, 1935 (Physalopteridae), Rhabdochona angusticaudata sp. n., Rhabdochona zacconis Yamaguti, 1935 (both Rhabdochonidae), Ascarophis arctica Polyanskiy, 1952 (Cystidicolidae) and Eustrongylides sp. larvae (Dioctophymatidae). The new species, $R$. angusticaudata sp. n., described from the intestine of the Japanese eel Anguilla japonica Temminck et Schlegel in the Renjoji River, Shikoku, is mainly characterised by the presence of 14-16 anterior prostomal teeth, non-bifurcated deirids with rounded ends, the length of the left spicule (300-384 $\mu \mathrm{m}$ long), the right spicule with a dorsal barb and non-filamented eggs. The species of Paraquimperia Baylis, 1934 and $A$. arctica are reported from Japan for the first time. Based on light and scanning electron microscopical examinations, some new morphological data on H. haze, H. anguillae, R. zacconis and A. arctica are provided.
\end{abstract}

Key words: parasitic nematode, Hysterothylacium, Pingus, Paraquimperia, Heliconema, Ascarophis, freshwater fish, Honshu, Shikoku, Hokkaido

Although the fauna of Japan is of particular interest from the zoogeographical point of view, the nematodes parasitising freshwater and brackish-water fishes in this country remain inadequately known (Moravec and $\mathrm{Na}$ gasawa 1989, Nagasawa 2016, 2017). In the period from 1984-2009, samples of nematodes from Japanese fishes from Honshu, Shikoku and Hokkaido were collected by the Japanese co-author of the present study. A part of this material (nematodes from marine fishes) has already been evaluated in previous publications (Moravec et al. 2010, 2012a). Results of the morphological-taxonomical evaluation of nematodes recovered from Japanese inland fishes are presented here. Besides one newly established species, the authors consider it important and useful to provide descriptions of the newly collected specimens belonging to some previously redescribed species, for which some new important morphological details and morphological and biometrical intraspecific variability are recorded.

\section{MATERIALS AND METHODS}

Fishes were collected from several localities in Honshu, Shikoku and Hokkaido, Japan, using various types of fishing gear, such as rod and line, hand nets, trap nets and cast nets. The following fish species were examined from different freshwater and brackish-water localitis: Acanthogobius flavimanus (Temminck et Schlegel) (Gobiidae) (10 specimens), Anguilla japonica Temminck et Schlegel (Anguillidae) (21), Channa argus (Cantor) (Channidae) (3), Gasterosteus aculeatus Linnaeus (Gasterosteidae) (12), Silurus asotus Linnaeus (Siluridae) (no data) and Tribolodon hakonensis (Günther) (Cyprinidae) (23).

The nematodes obtained were washed in physiological saline and fixed and preserved in $70 \%$ ethanol. For light microscopical examination, the nematodes were cleared in glycerine. Drawings were made with the aid of a Zeiss drawing attachment. Specimens used for scanning electron microscopy (SEM) were postfixed in $1 \%$ osmium tetroxide (in phosphate buffer), dehydrated through a graded acetone series, critical-point-dried and sputter-coated with gold; they were examined using a JEOL JSM-7401F scanning electron microscope at an accelerating voltage of $4 \mathrm{kV}$ (GB low mode).

All measurements are in micrometres unless otherwise indicated. The type and voucher specimens have been deposited in the Helminthological Collection of the Institute of Parasitology, Biology Centre of the Czech Academy of Sciences, České Budě- 

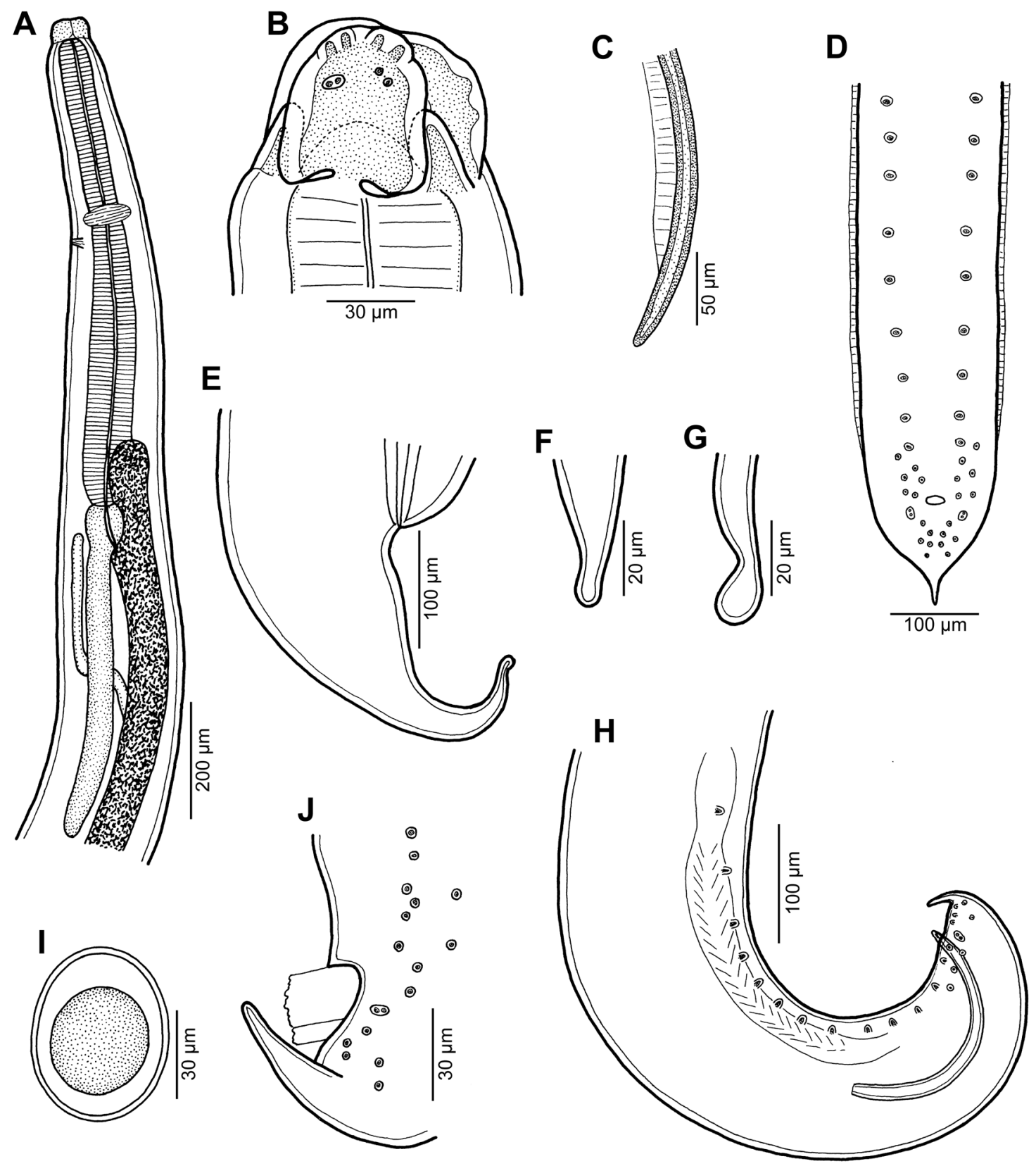

Fig. 1. Hysterothylacium haze (Machida, Takahashi et Masuuchi, 1978) from Acanthogobius flavimanus (Temminck et Schlegel). $\mathbf{A}$ - anterior end of male, lateral view; $\mathbf{B}$ - cephalic end of male, subventral view; $\mathbf{C}$ - distal end of spicule, lateral view; $\mathbf{D}$ - posterior end of male, ventral view; $\mathbf{E}$ - tail of female, lateral view; $\mathbf{F}, \mathbf{G}$ - two different shapes of female tail; $\mathbf{H}$ - posterior end of male, lateral view; I - egg; J - distribution of caudal papillae near cloaca, lateral view.

jovice, Czech Republic (IPCAS). The higher nematode classification used is that of Keys to the Nematode Parasites of Vertebrates (Anderson et al. 2009). The fish nomenclature adopted follows FishBase (Froese and Pauly 2018).

\section{RESULTS}

Anisakidae Railliet et Henry, 1912

Hysterothylacium haze (Machida, Takahashi et Masuuchi, 1978) Deardorff et Overstreet, 1981

Figs. 1-3

Description. Medium-sized, whitish nematodes with slightly transversely striated cuticle (Figs. 2E,F, 3B,D, E).
Maximum width in posterior part of body. Lips almost equal in size, slightly longer than wide, with wide lateral flanges and narrow bases; pulp with 2 anteriorly protruding projections, each divided into 2 lobes. Dorsal lip with 2 subdorsal double papillae; each subventral lip with 1 double subventral papilla, one small single papilla and amphid situated laterally (Figs. 1B, 2A-D). Interlabia well developed, about 1/2 length of lips (Figs. 1B, 2A-D). Lateral alae very narrow, starting slightly posterior to level of lip bases, extending posteriorly in both sexes as cordons almost to end of tail (Figs. 2A,E-G, 3A,D,E). Oesophagus long, slightly broader posteriorly. Nerve ring encircles oesophagus at its anterior part. Ventriculus small, almost spherical; ventricular appendix long, narrow. Intestinal 

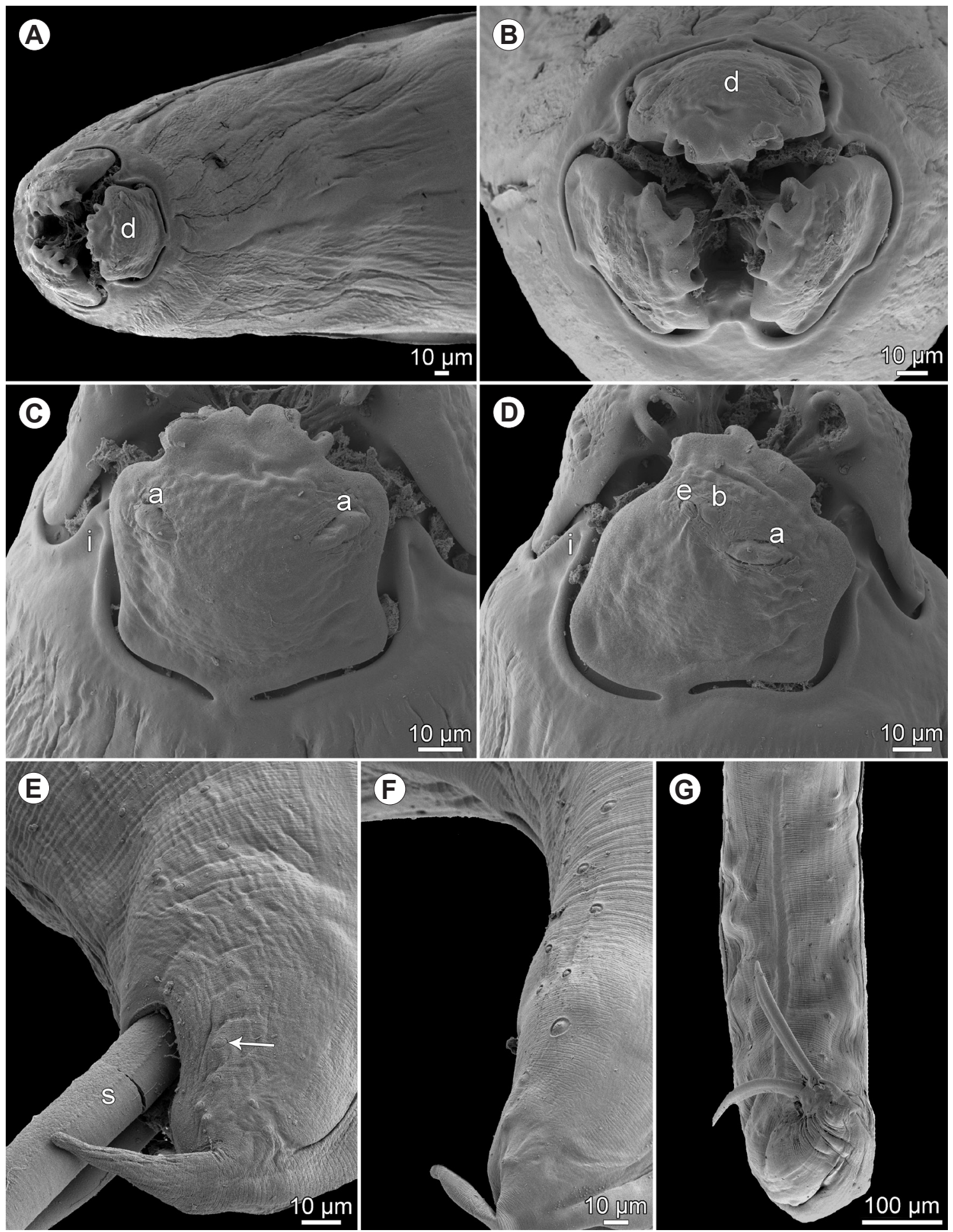

Fig. 2. Hysterothylacium haze (Machida, Takahashi et Masuuchi, 1978) from Acanthogobius flavimanus (Temminck et Schlegel), scanning electron micrographs. A - anterior end of female with distinct lateral alae, dorsal view; $\mathbf{B}$ - cephalic end, apical view; $\mathbf{C}$ - dorsal lip; D - subventral lip; E - caudal end of male, lateral view (arrow indicates double papilla); $\mathbf{F}$ - distribution of papillae on caudal end, lateral view (another specimen; arrow indicates double papilla); G - posterior end of male, ventral view. Abbreviations: a - double cephalic papilla; $\mathrm{b}$ - single cephalic papilla; $\mathrm{d}$ - dorsal lip; $\mathrm{e}$ - amphid; $\mathrm{i}$ - interlabium; $\mathrm{s}$ - spicule.

caecum short, wide (Fig. 1A). Excretory pore just posterior to nerve ring. Tail of both sexes conical.

Male (7 specimens). Length of body $7.5-19.2 \mathrm{~mm}$, maximum width 204-544; width just posterior to base of lips 75-150. Lips 57-87 long; length of interlabia 27-39. Length of oesophagus $789-1,700$, representing $9-12 \%$ of body length; maximum width $60-150$. Nerve ring and excretory pore 367-544 and 408-707, respectively, from anterior extremity. Ventriculus 66-122 × 63-150; ventricular appendix 422-1,645 long, maximum width 45-109. Intestinal caecum 159-571 long, maximum width 51-163. Caecum to ventricular appendix length ratio $1: 2-4$. Posterior 

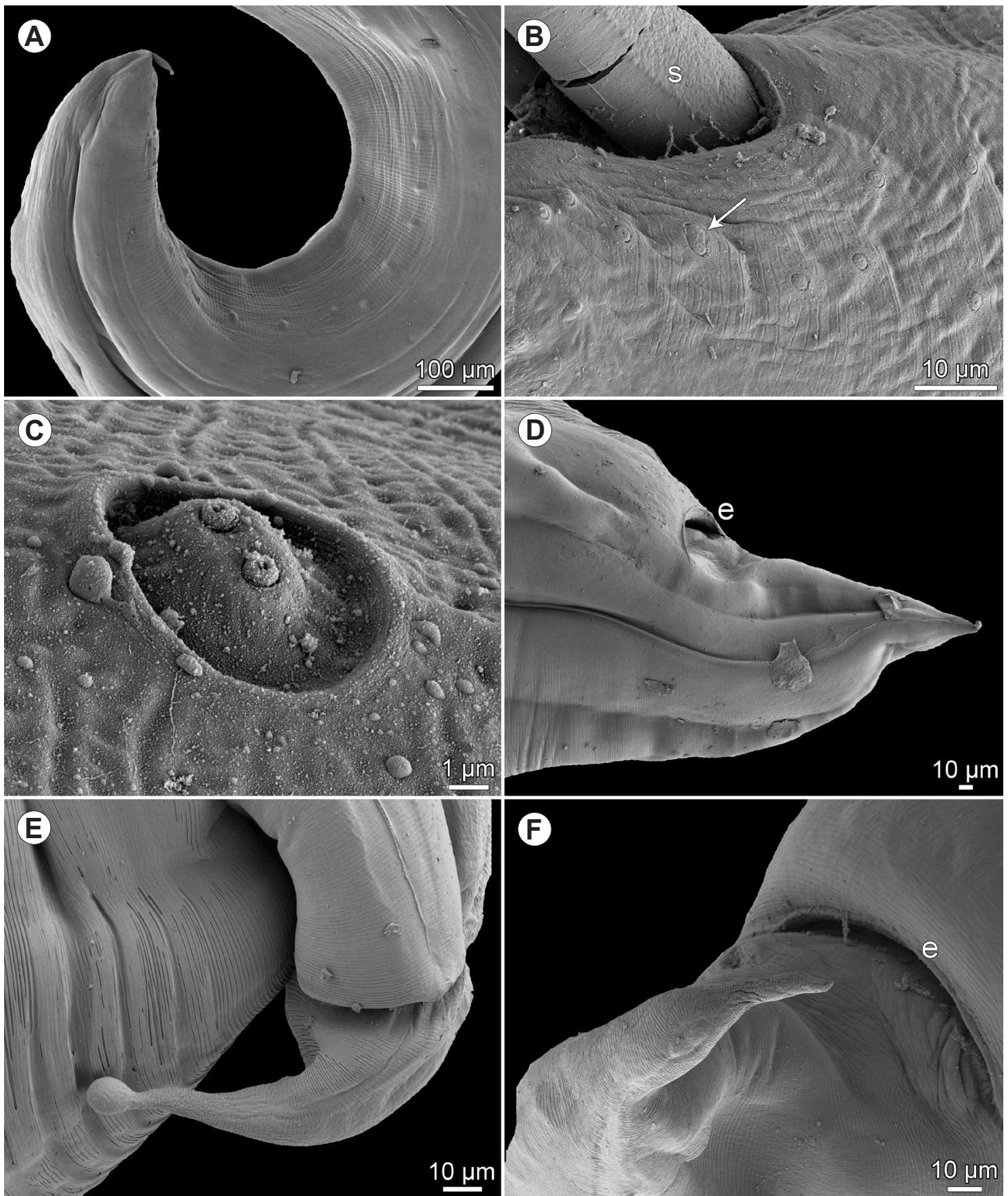

Fig. 3. Hysterothylacium haze (Machida, Takahashi et Masuuchi, 1978) from Acanthogobius flavimanus (Temminck et Schlegel), scanning electron micrographs. A - posterior end of male, sublateral view; B - region of cloaca, lateral view (arrow indicates double papilla); $\mathbf{C}$ - double papilla; $\mathbf{D}$ - tail of female, lateral view; $\mathbf{E}$ - bulbously inflated tail tip of female; $\mathbf{F}$ - non-inflated tail tip of female. Abbreviations: e - anus; s - spicule.

end of body curved ventrally. Spicules equal, alate except for pointed tip, 381-516 long, representing $2.4-5.5 \%$ of body length (Fig. 1C,H). Total of 21-29 pairs of small subventral papillae present, $15-20$ being preanals, 2 adanals and 6 postanals; papillae of several posteriormost preanal and postanal pairs very small, arranged in 2 longitudinal rows; papillae of first postanal pair doubled (Fig. 1D,H,J). Tail conical, 66-129 long, markedly narrowed at its distal portion; tip rounded (Figs. 1D,H,J, 2E-G, 3A).

Female (5 gravid specimens). Length of body 12.6$21.6 \mathrm{~mm}$, maximum width $422-734$; width just posterior to base of lips 122-177. Lips 75-111 long. Length of interlabia 39-48. Length of oesophagus $1.12-1.85 \mathrm{~mm}$, representing $6-13 \%$ of body length; maximum width $90-177$. Nerve ring and excretory pore 435-898 and 490-1,047, respectively, from anterior extremity. Ventriculus 57-122 $\times 57-150$; ventricular appendix 503-1,727 long, maximum width 82-150. Intestinal caecum 204-530 long, maximum width 95-150. Caecum to ventricular appendix length ratio $1: 2-4$. Vulva pre-equatorial, $4.5-6.7 \mathrm{~mm}$ from anterior end of body, at $25-36 \%$ of body length. Vagina directed posteriorly from vulva. Uterus contains numerous oval, 
thin-walled, unembryonated eggs 60-66 long and 51-60 wide (Fig. 1I). Tail conical, 204-258 long; tip rounded, sometimes bulbously expanded (Figs. 1E-G, 3D-F).

Host: Yellowfin goby, Acanthogobius flavimanus (Gobiidae, Perciformes).

Site of infection: Body cavity.

Locality: Lake Hamana (brackish-water), Hamamatsu, Shizuo-

ka Prefecture, Honshu, Japan (collected 16 November 2009).

Prevalence and intensity: 40\% (4 fish infected, 15.2-21.0 $\mathrm{cm}$ in total length [TL]/10 fish examined, $14.5-21.0 \mathrm{~cm} \mathrm{TL}$ );

1-43 (mean 12) nematode specimens (adults and larvae).

Deposition of voucher specimens: IPCAS N-1152.

Remarks. Thynnascaris (=Hysterothylacium) haze was described by Machida et al. (1978) from A. flavimanus in Tokyo Bay (reported as the Bay of Tokyo), where it was associated with mass mortalities of this fish during summer seasons in 1973-1975 (Takahashi et al. 1976, 1977). Based on specimens collected from A. flavimanus captured in a brackish-water region of Lake Hamana, Shizuoka Prefecture, Yoshinaga et al. (1988, 1989a,b) studied in detail the morphology of this nematode, including the morphogenesis of larvae, and carried out some experimental infections of yellowfin goby and aquatic invertebrates to elucidate its life cycle and transmission.

Results of the present study, especially the use of SEM, made it possible to study in detail some taxonomically important but previously insufficiently documented or unreported morphological features in H. haze, such as amphids, the presence of postanal double papillae in the male, the exact numbers and distribution of male caudal papillae and the variability in the shape of the female tail tip.

The life cycle pattern of $H$. haze markedly differs from those of other congeners in that the adult worms are present and the oviposition occurs in the body cavity, rather than in the intestine, of the definitive host (Machida et al. 1978, Yoshinaga et al. 1988, 1989a). This phenomenon in H. haze was considered by Anderson (1988) to be an example of extreme precocity in which the fish intermediate host has also become a "final host" (correctly the definitive host in the conception of Odening 1976). According to Moravec (2013), another case of precocity in anisakid nematodes is apparently the record of adults of Hysterothylacium sp. in marine prawns Pandalus borealis Krøyer by Margolis and Butler (1954).

However, the present knowledge of the development and transmission of Hysterothylacium spp. is still fragmentary (Anderson 2000). Therefore, it cannot be excluded that $H$. haze exhibits a variable development with alternative cycles, similar to that in Cucullanus truttae Fabricius, 1794 (see Moravec 2013), where the development may be either with the participation of the obligate intermediate host (A. flavimanus) and the definitive host (unknown fish species), or the complete development is realised in $A$. $f l a-$ vimanus. In such a case, A. flavimanus would be an isochronous polyvalent host (Odening 1976).

According to Machida et al. (1978) and Yoshinaga et al. (1989a), the eggs of $H$. haze deposited in the body cavity are released into the water with the death of infected gobies where they may infect other gobies directly, or indirectly through invertebrate hosts. However, it is possible that infected gobies, harbouring $H$. haze larvae and adults, are eaten by some predatory fish species, which may then serve as a definitive or a postcyclic host. Taking into account this presumption, more attention should be paid to the transmission of this parasite in the localities where $H$. haze occurs in gobies. Some ecological aspects of $H$. haze were reported by Yoshinaga (1992).

\section{Quimperiidae Gendre, 1928}

\section{Paraquimperia sp.}

Figs. 4, 5

Description of nongravid female (1 specimen). Medium-sized nematode with anterior end of body dorsally bent. Anterior part of body with broad (maximum width 54) lateral alae initiating near anterior extremity; behind deirids these become narrower and extend along major part of body as narrow lateral alae (Figs. 4A-C, 5C). Body length $9.40 \mathrm{~mm}$, maximum width 218 . Oral aperture surrounded by 4 submedian cephalic papillae and 2 lateral amphids (Fig. 5A). Inner surface of oral aperture lined with cuticular mound consisting of three (1 dorsal and 2 ventrolateral) sectors; both ends of each sector strengthened to form small tooth-like structure oriented anteriorly; bottom of small buccal cavity formed by 3 flat sectors of oesophagus, each armed with forwardly directed tooth (Figs. 4C, 5B). Anterior end of oesophagus forming small pharynx 33 long and 51 wide (Fig. 4A-C). Oesophagus consisting of anterior narrower muscular and posterior wider musculo-glandular part; anterior part of oesophagus without pharynx 476 long, 57 wide, posterior part 394 long and 90 wide (Fig. 4A, B); entire oesophagus including pharynx 903 long, representing $10 \%$ of body length. Nerve ring, deirids and excretory pore 408, 789 and 1,034, respectively, from anterior extremity. Vulva situated in posterior part of body, at $6.96 \mathrm{~mm}$ from anterior extremity (at 74\% of body length). Vulva slightly elevated. Vagina directed anteriorly from vulva. Uterus empty. Tail straight, conical, 354 long; lateral outlets of phasmids located somewhat behind mid-length of tail, appearing as small lateral papillae.

Host: Japanese eel, Anguilla japonica (Anguillidae, Anguilliformes). Site of infection: Intestine.

Locality: Renjoji River (freshwater middle-ridges), Ainan, Ehime Prefecture, Shikoku, Japan (collected 25 June 2007).

Prevalence and intensity: 9\% (1 fish infected, $47.5 \mathrm{~cm}$ TL

/11 fish examined, 35.2-53.2 cm TL); 1 nematode.

Deposition of voucher specimen: Not deposited (used for SEM).

Remarks. The general morphology of the only available specimen from $A$. japonica, especially the presence of wide cervical alae, shape of the oesophagus and the structure of the mouth, shows that it belongs to the quimperiid genus Paraquimperia Baylis, 1934. Although details of its mouth are not readily visible on the available SEM micrograph (Fig. 5B), it is clear that the structure of the mouth is much the same as that of Paraquimperia tenerrima (von Linstow, 1878) (see Fig. 6A,B). 

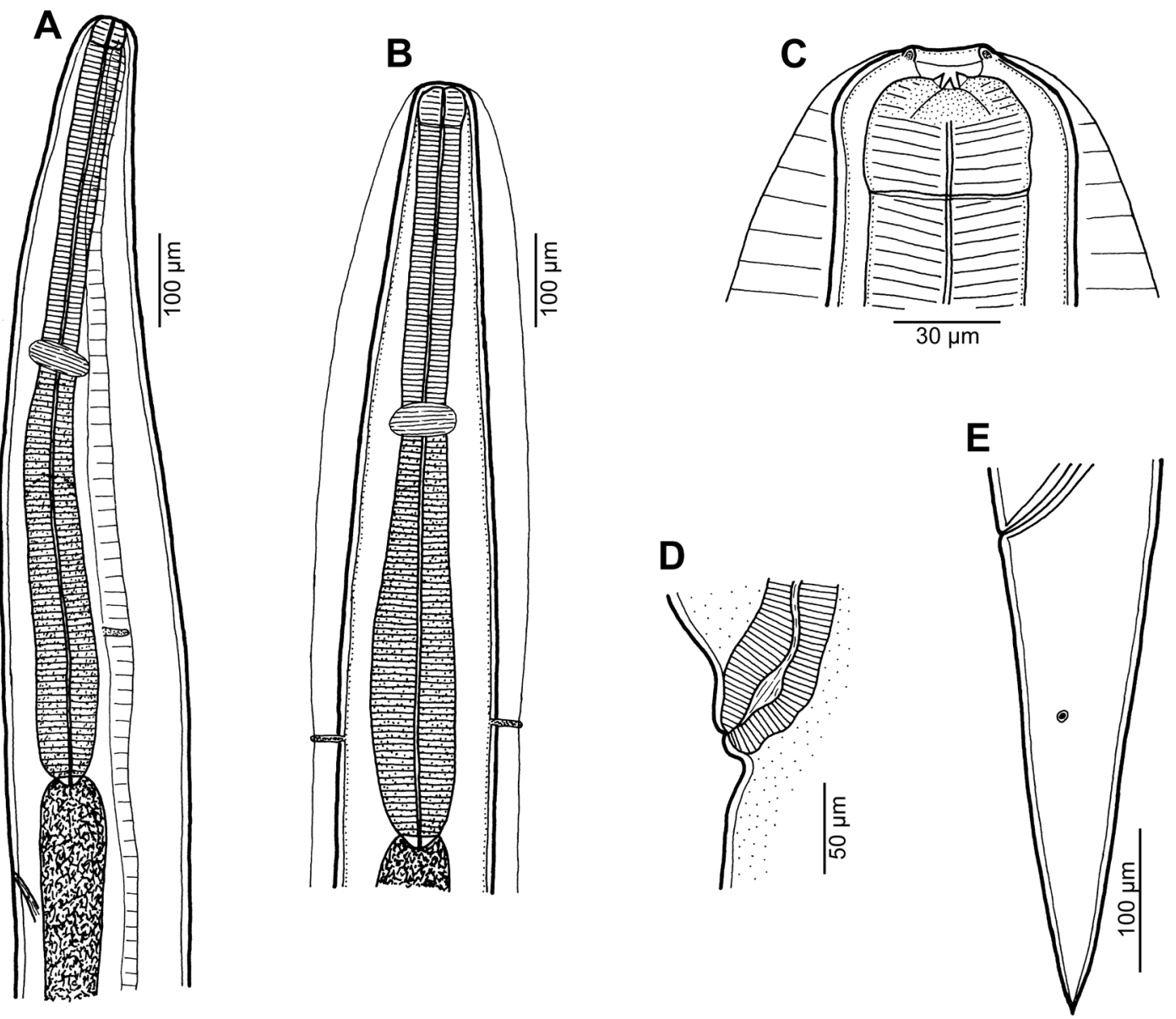

Fig. 4. Paraquimperia sp., nongravid female from Anguilla japonica Temminck et Schlegel. A, B - anterior part of body, lateral and dorsoventral views, respectively; $\mathbf{C}$ - cephalic end, dorsal view; D - vulva, lateral view; $\mathbf{E}$ - tail, lateral view.

At present, the genus Paraquimperia contains three valid species, all specific parasites of freshwater eels (Anguilla spp.): Paraquimperia africana Moravec, Boomker et Taraschewski, 2000 parasitising Anguilla mossambica Peters in South Africa; Paraquimperia anguillae Karve, 1941 from Anguilla bengalensis (Grey) in India; and $\mathrm{Pa}$ raquimperia tenerrima [syn. Paraquimperia aditum $(\mathrm{Mu}-$ eller, 1934)] from Anguilla anguilla (Linnaeus) and Anguilla rostrata (Le Sueur) in Europe and North America, respectively (Moravec et al. 2000). However, interspecific features are found in males, so that the present single specimen (a nongravid female) from A. japonica in Japan cannot be identified to species by morphological features. We can only speculate that it might belong to the Holarctic species Paraquimperia tenerrima, but it will be necessary to obtain conspecific males from $A$. japonica to confirm this presumption. Nevertheless, the finding of Paraquimperia sp. in Japan represents the first record of a species of this genus in eastern Asia.

\section{Pingus sinensis Hsü, 1933}

Description of gravid female (1 specimen). Length of body $5.40 \mathrm{~mm}$, maximum width at region of oesophagus 135. Cephalic end rounded, bearing four submedian papillae and lateral amphids. Cephalic end forms two lateral lobes from which broad lateral alae extend posteriorly along body; alae broadest in oesophagus region. Oesophagus with short, slightly outlined pharynx 15 long and 36 wide; anterior portion of oesophagus (without pharynx) anterior to nerve ring muscular, 210 long and 48 wide; posterior muscular-glandular portion somewhat broader, 366 long and 84 wide; entire oesophagus including pharynx 591 long, representing $11 \%$ of body length. Nerve ring, deirids and excretory pore 218, 466 and 558, respectively, from anterior extremity. Vulva postequatorial, situated $3.26 \mathrm{~mm}$ from anterior end of body (at $60 \%$ of body length); anterior vulval lip somewhat elevated. Vagina directed anteriorly from vulva. Amphidelphic. Anterior ovary extending to short distance posterior to oesophagus, posterior ovary extends to mid-length of tail. Eggs in uterus arranged in one file. Eggs unembryonated, oval, smooth, size $66-81 \times$ 39-51. Tail conical, 258 long, sharply pointed.

Host: Snakehead, Channa argus (Channidae, Perciformes).

Site of infection: Pyloric caeca.

Locality: Kamo River (a tributary of the Ashida River), Fukuyama, Hiroshima Prefecture, Honshu, Japan (collected 26 November 2008).

Prevalence and intensity: 1 fish infected, $61.5 \mathrm{~cm}$ TL/ 1fish examined; 1 nematode.

Deposition of voucher specimen: Not deposited (used for SEM). 

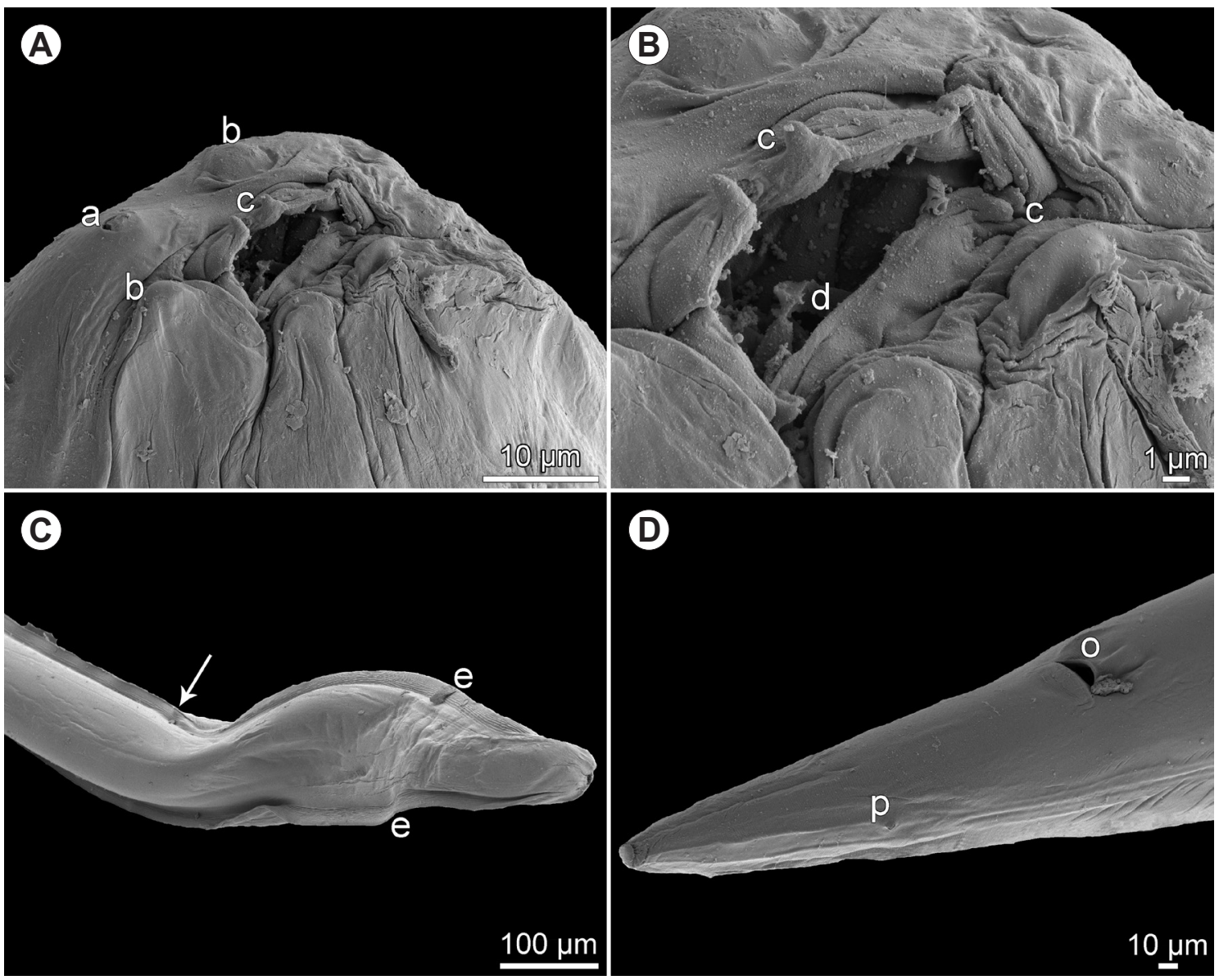

Fig. 5. Paraquimperia sp. from Anguilla japonica Temminck et Schlegel, scanning electron micrographs of nongravid female. A - cephalic end, sub-dorsoventral view; B - region of mouth, subapical view; C - anterior portion of body, dorsal view (arrow indicates deirid); D - tail, sublateral view. Abbreviations: a - amphid; b - cephalic papilla; c - two tooth-like structures of neighbouring sectors of mouth mound; $\mathrm{d}$ - oesophageal tooth; $\mathrm{e}$ - lateral alae; $\mathrm{o}$ - anus; $\mathrm{p}$ - phasmid.

Remarks. The morphology of the present nematode is in agreement with the redescription of $P$. sinensis by Shimazu et al. (2000), who also studied this species by SEM. Therefore, no illustrations of the present specimen are provided. This species was originally described by Hsü (1933) from C. argus in China, later it was recorded a few times from the same host species in China and eastern Russia (Amur River basin) (e.g. Wu 1956, Dogel and Akhmerov 1959, Wang et al. 1978, Moravec et al. 2003) and by Ky (1971) and Moravec and Sey (1988) from Channa maculata (Lacépède) from North Vietnam.

Shimazu et al. (2000) were the first to record and describe $P$. sinensis from C. argus in Japan (Imperial Palace in Tokyo). Later, this nematode was reported from the same host species in the Nagara River, Gifu Prefecture and from Lake Biwa, Shiga Prefecture (Anonymous 2002, Grygier and Urabe 2003, Grygier and Hirasawa 2011). Although snakeheads (Channidae) were not naturally distributed in Japan (Froese and Pauly 2018), C. argus was introduced from Korea as early as in 1923 and, most likely, the nematode also came to Japan from Korea (Shimazu et al. 2000).

Physalopteridae Railliet, 1893

Heliconema anguillae Yamaguti, 1935

Fig. 7
Description. Medium sized, whitish nematodes with thick, transversely striated cuticle. Cephalic end rounded. Cuticle in cephalic region inflated to form cephalic vesicle extending posteriorly to about level of deirids and anteriorly forming somewhat extended collar which may exceed pseudolabia anteriorly (Fig. 7A,B). Oral aperture dorsoventrally elongate, oval, rather large, surrounded by 2 massive, rounded lateral pseudolabia. Each pseudolabium bears 2 large submedian (dorsolateral and ventrolateral) cephalic papillae and oval lateroterminal depression filled with irregularly lobular mass; small lateral amphids situated between both cephalic papillae (Fig. 7A,B). Inner surface of each pseudolabium with elongate lateral mound bearing marked triangular terminal lateral tooth (internolateral tooth) situated immediately near inner border of cephalic depression and simple flat tooth at each dorsoventral extremity; no denticles present near terminal lateral teeth (Fig. 7A,B). Buccal cavity short. Oesophagus divided into short, narrow anterior muscular portion and much longer, wide glandular portion. Nerve ring encircles muscular oesophagus at its posterior half. Small simple deirids situated at about level of nerve ring. Excretory pore slightly anterior to anterior end of glandular oesophagus. Tail of both sexes with rounded tip. 


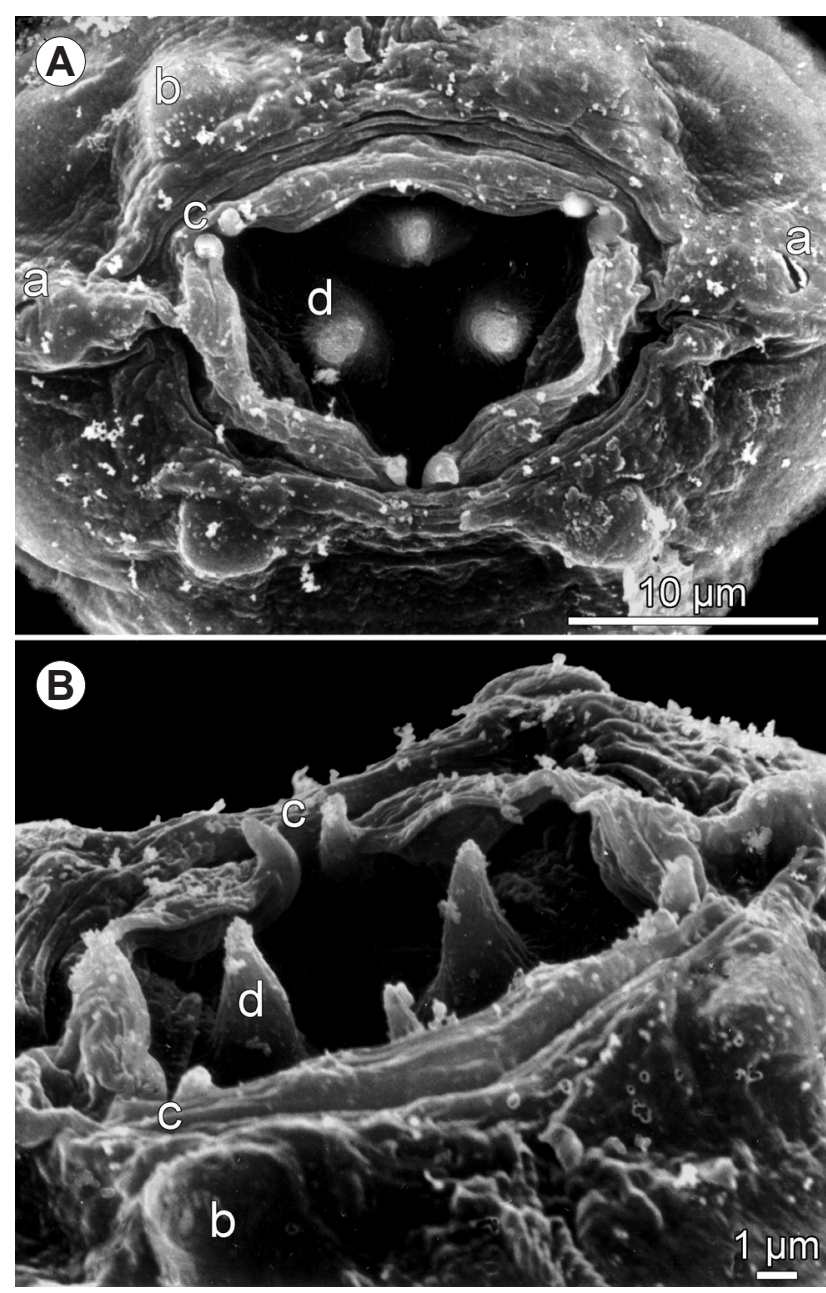

Fig. 6. Paraquimperia tenerrima (von Linstow, 1878) from Anguilla anguilla (Linnaeus), Czech Republic, scanning electron micrographs of mouth. A - apical view; B - subdorsal view. $A b-$ breviations: $\mathrm{a}$ - amphid; $\mathrm{b}$ - cephalic papilla; $\mathrm{c}$ - two tooth-like structures of neighbouring sectors of mouth mound; $d-$ oesophageal tooth.

Male (5 specimens). Length of body $28.7-33.4 \mathrm{~mm}$, maximum width 462-612. Pseudolabia 12-15 long. Cephalic vesicle approximately $0.6-1.7 \mathrm{~mm}$ long and 204 340 wide. Buccal cavity 39-51 long. Entire oesophagus 3.44-3.96 mm long, representing $11-12 \%$ of body length; muscular oesophagus 476-503 long and 81-109 wide; glandular oesophagus 2.9-3.5 mm long and 190-245 wide; length ratio of two parts of oesophagus $1: 6-7$. Nerve ring, deirids and excretory pore 299-340, 299-326 and 394-517 from anterior extremity, respectively. Caudal end spirally coiled, provided with lateral alae supported by 4 pairs of subventral pedunculate preanal papillae arranged in couples, and 5 single pairs of subventral postanal papillae, which are rather large and pedunculate; an additional pair of small postanal sessile papillae situated ventrally slightly posterior to level of last subventral postanal pair (Fig. $7 \mathrm{C}-\mathrm{F}$ ); pair of very small ventral sessile postanal papillae located just posterior to cloacal aperture present in some specimens but absent in others (Fig. 7C,E). Pair of minute phasmids present posterior to ventral pair of posteriormost postanal papillae (Fig. 7E,F). Ventral surface between pos- teriormost ventral postanal papillae and phasmids elevated to form distict small protuberance (Fig. 7E,F). Cloacal lips somewhat elevated (Fig. 7C,E). Ventral precloacal surface with about 14 longitudinal tesselated ridges (area rugosa) (Fig. 7C-E). Spicules unequal and dissimilar; left spicule 544-748 long, with sharply pointed tip; right spicule broader, boat-shaped, 240-306 long, tapered towards distal tip. Length ratio of spicules $1: 1.9-2.7$. Length of tail 299-394.

Female (5 gravid specimens). Length of body 40.2-52.4 mm, maximum width 612-966. Pseudolabia 15-21 long. Cephalic vesicle 340-381 wide. Buccal cavity 45-68 long. Entire oesophagus $3.8-4.7 \mathrm{~mm}$ long, representing 9\% of body length; muscular oesophagus 503-680 long and 78-95 wide; glandular oesophagus 3.3-4.0 mm long and 177-258 wide; length ratio of two parts of oesophagus $1: 6$. Nerve ring, deirids and excretory pore 340-367, 272-313 and 462-571 from anterior extremity, respectively. Vulva situated 17.8-23.2 mm from anterior end of body, at $44 \%$ of body length. Vulval lips not elevated.Vagina narrow, muscular, directed posteriorly from vulva. Uteri containing numerous oval, thick-shelled, embryonated (larvated) eggs; eggs 45-51 × 27-30, with wall 3 thick. Tail short, 190-204, with rounded tip.

Host: Japanese eel, Anguilla japonica (Anguillidae, Anguilliformes). Site of infection: Stomach.

Locality: Misho Cove (near the mouth of the Renjoji River), Ainan, Ehime Prefecture, Shikoku, Japan (collected 16 June 2007).

Prevalence and intensity: 5 fish infected, $33.0-44.6 \mathrm{~cm}$ TL $/ 5$ fish examined; 31-185 (mean 95) nematodes per fish.

Deposition of voucher specimens: IPCAS N-1091.

Remarks. Heliconema anguillae, originally described by Yamaguti (1935) from A. japonica from an unknown locality in Japan, was subsequently synonymised by Ogden (1969) with Heliconema longissimum (Ortlepp, 1922). However, Katahira and Nagasawa (2015) resurrected this species and provided its detailed redescription based on newly collected specimens from $A$. japonica in Misho Cove, Ehime Prefecture, western Japan. The morphology of the present nematodes, collected from the same host species and the same locality, is in agreement with the species redescription, but the specimens are much larger (males and females approximately 29-33 and 40-52 mm long, respectively vs 16-23 and 20-29 mm), extending the biometrical variability of this species considerably.

While describing Heliconema hainanensis $\mathrm{Li}$, Liu et Zhang, 2013 (correctly hainanense - see International Code of Zoological Nomenclature), Li et al. (2013) provided a key to species of Heliconema Travassos, 1919. However, two congeneric species, Heliconema africanum (von Linstow, 1899) and Heliconema ahiri Karve, 1941, both parasites of freshwater eels (Anguilla spp.) in South Africa and India, respectively, were not included; the former species was assigned to Heliconema and the latter one was revalidated only in 2013 (Moravec et al. 2013a,b). Although the morphology of these two species is very similar to that of $H$. anguillae, $H$. africanum differs from this 

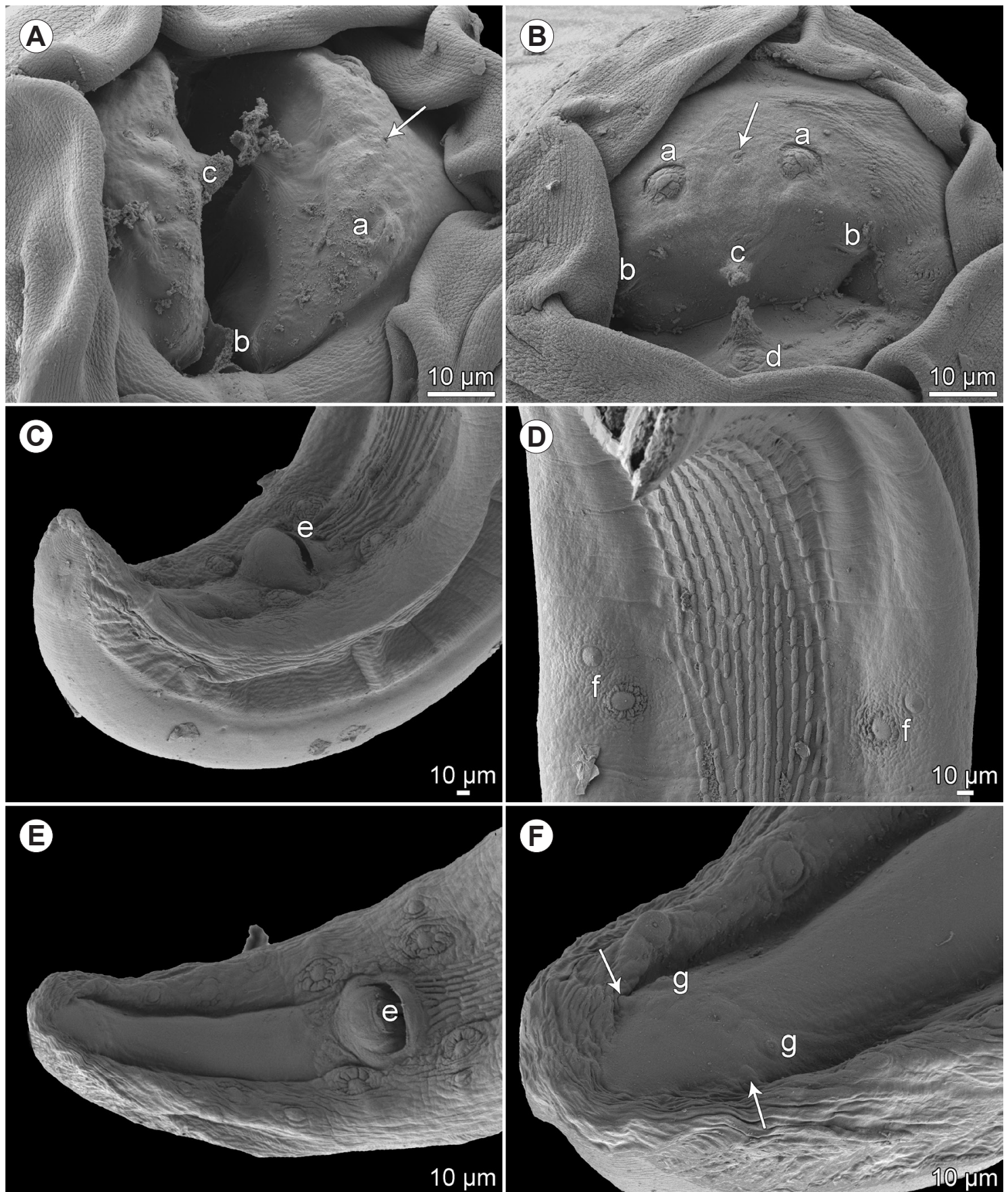

Fig. 7. Heliconema anguillae Yamaguti, 1935 from Anguilla japonica Temminck et Schlegel, scanning electron micrographs. A, B cephalic end, subapical views (arrow indicates amphid); $\mathbf{C}$ - tail of male, sublateral view; D - ventral precloacal ridges and first two pairs of preanal papillae, ventral view; $\mathbf{E}$ - tail of male, ventral view; $\mathbf{F}$ - tail tip of male, ventral view (arrows indicate phasmids). $A b$ breviations: $\mathrm{a}$ - cephalic papilla; $\mathrm{b}$ - submedian tooth; $\mathrm{c}$ - lateral tooth; $\mathrm{d}$-pseudolabial lateroterminal depression; $\mathrm{e}$ - cloacal aperture; $\mathrm{f}$ - papillae of first two preanal pairs; $\mathrm{g}$ - small ventral postanal papilla.

east-Asian species mainly in the number and character of postanal papillae (the pair of small sessile papillae located just posterior to the cloaca is absent), whereas $H$. ahiri mainly in the presence of minute denticles on pseudolabia in the region between the terminal lateral tooth and the submedian flat teeth and in the number and character of postanal papillae. In contrast to the three above-mentioned species, $H$. hainanense, a parasite of anguilliform fishes of the families Congridae and Muraenesocidae in the South China Sea, has each pseudolabium without a subterminal lateral depression and all six pairs of postanal papillae are subventral and pedunculate.

Heliconema anguillae is a brackish-water parasite which uses intertidal crabs as its intermediate hosts and A.japon$i c a$ as its definitive hosts (Katahira and Nagasawa 2015, see Nagasawa and Katahira 2017). Katahira et al. (2011) carried out some ecological observations on $H$. anguillae (reported as H. longissimum) in A. japonica in Misho Cove and the lower reaches of the Renjoji River. 

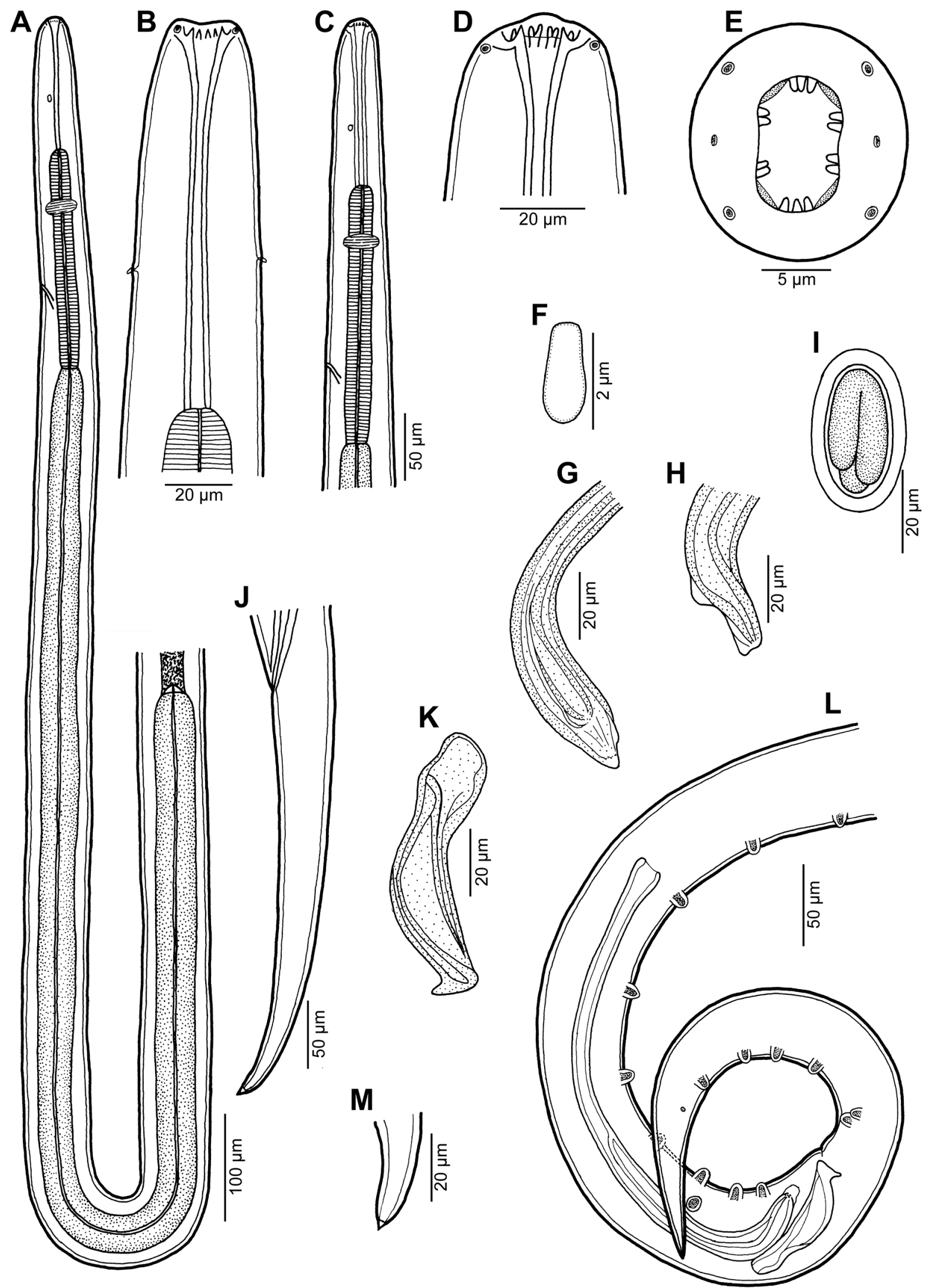

Fig. 8. Rhabdochona angusticaudata sp. n. from Anguilla japonica Temminck et Schlegel. A - anterior part of male body, lateral view; $\mathbf{B}, \mathbf{C}$ - anterior end of male, dorsoventral and lateral views, respectively; $\mathbf{D}$ - cephalic end of female, lateral view; $\mathbf{E}$ - cephalic end of male, apical view; $\mathbf{F}$ - deirid; $\mathbf{G}, \mathbf{H}$ - distal end of left spicule (different specimens), lateral views; I - egg; J - female tail, lateral view; $\mathbf{K}$ - right spicule, lateral view; $\mathbf{L}$ - posterior end of male, lateral view; $\mathbf{M}$ - tail tip of female. 
Rhabdochonidae Travassos, Artigas et Pereira, 1928

Rhabdochona angusticaudata sp. n.

Figs. 8-10

ZooBank number for species:

urn:Isid:zoobank.org:act:32A17EE6-4EFE-4416-BF90-A34F066B94CE

Description. Medium-sized nematodes with finely transversely striated cuticle Fig. 10A,B,F). Lateral alae absent. Mouth roughly hexagonal. Four small submedian cephalic papillae, 2 lateral amphids and 4 submedian sublabia present (Figs. 8E, 9A-E). Prostom funnel-shaped, without basal teeth (Fig. 8B,D); anterior teeth 14-16 in number, 3-4 dorsal, 3-4 ventral and 4 lateral (arranged in 2 pairs) on either side (Figs. 8B-E, 9A-E, 10A). Deirids small, non-bifurcated, with rounded ends, situated slightly asymmetrically approximately at mid-length of vestibule (Figs. 8A-C,F, 9F, 10B). Excretory pore at level of posterior part of muscular oesophagus (Figs. 8A,C, 10A). Tail of both sexes conical, slender, with sharply pointed tip.

Male (2 complete and 1 incomplete specimens; holotype; measurements of paratypes in parentheses): Length of body $8.42 \mathrm{~mm}$ (13.6 $\mathrm{mm}$ in complete specimen), maximum width 78 (81). Prostom 21 (18-21) long and 15 (15) wide in lateral view. Length of vestibule including prostom 126 (117-126). Muscular oesophagus 231 (204-228) long, 24 (24-27) wide, length of glandular oesophagus 1.18 (1.35-1.40) mm, width 45 (48-60). Nerve ring, excretory pore and deirids 207 (177-207), 297 (270-312) and 80 (63-66), respectively, from anterior extremity. Preanal papillae: 9 subventral and 1 lateral pairs present; lateral pair situated at level of third subventral pair (counting from cloacal opening). Of 6 postanal pairs of papillae, second pair situated more laterally, remaining pairs subventral; lateral pair just posterior to first subventral pair (Figs. 8L, 10C). Minute phasmids situated laterally short distance posterior to level of last pair of postanal papillae (Figs. 8L, 10D). Precloacal ventral cuticular ornamentations (area rugosa) absent. Large (left) spicule well sclerotised, 384 (300) long; length of its shaft 183 (144), representing 48\% (48\%) of whole spicule length; distal tip moderately widened, lanceolate (Fig. 8G,H,L). Small (right) spicule boat-shaped, 87 (81) long, with distinct dorsal barb at distal tip (Fig. 8K, L). Length ratio of spicules $1: 4.4(1: 3.7)$. Length of tail 300 (255).

Female (1 gravid specimen with mature eggs, allotype): Length of body $19.1 \mathrm{~mm}$, maximum width 165 . Prostom 24 long and 18 wide. Length of vestibule including prostom 123. Muscular oesophagus 306 long, 27 wide, length of glandular oesophagus $1.63 \mathrm{~mm}$, width 63. Nerve ring, excretory pore and deirids 219, 300 and 90, respectively, from anterior extremity. Vulva equatorial, $9.63 \mathrm{~mm}$ from anterior extremity (at 50\% of body length) (Fig. 10F); vagina muscular, 66 long, directed posteriorly from vulva. Uterus filled with many eggs. Fully developed eggs larvated, oval, thick-walled, size 39-42 × 21-24, with smooth surface, without filaments; thickness of egg wall 4 (Fig. 8I). Tail conical, slender, 333 long, ending in sharp cuticular spike (Figs. 8J,M, 10E).
Type host: Japanese eel, Anguilla japonica (Anguillidae, Anguilliformes).

Site of infection: Intestine.

Type locality: Renjoji River (brackish-water area and freshwater middle-reaches), Ainan, Ehime Prefecture, Shikoku, Japan (collected 16 and 25 June 2007).

Total prevalence and intensity: 19\% (3 fish infected/16 fish examined); 9 nematodes. Brackish-water area near the river mouth: 2 fish infected, 46.5 and $49.4 \mathrm{~cm} \mathrm{TL} / 5$ fish examined, 32.0-49.4 cm TL; 1 and 4 nematodes. Freshwater middle-reaches of the river: $9 \%$ ( 1 fish infected, $47.5 \mathrm{~cm} \mathrm{TL} / 11$ fish examined, $35.2-53.2 \mathrm{~cm} \mathrm{TL}) ; 4$ nematodes.

Deposition of type specimens: IPCAS N-1157 (mounted on SEM stubs).

Etymology: The specific name angusticaudata (= narrow-tailed) is the Latin adjective, relating to the characteristic feature of this species, i.e., a markedly narrow female tail.

Remarks. At present the genus Rhabdochona Railliet, 1916 comprises about 100 species parasitising freshwater fishes in all zoogeographical regions (Moravec 2010). The general morphology of $R$. angusticaudata sp. n., especially the number of prostomal teeth and no ornamentations at the tip of the tail, indicates that this species belongs to the nominotypic subgenus Rhabdochona, as defined by Moravec (1975).

Most species of this subgenus possess bifurcate deirids and only a few of them, e.g. Rhabdochona acuminata (Molin, 1860), Rhabdochona marcusenii Moravec et Jirků, 2014 or Rhabdochona fabianae Ramallo, 2005, have simple, rod-like deirids (Cremonte et al. 2002, Moravec and Jirků 2014, Ramallo 2005) or the deirids are hammer-shaped (Rhabdochona papuanensis Moravec, Kíha et Kuchta, 2008) or oval, leaf-like (Rhabdochona pseudomysti Moravec et Yooyen, 2011) (see Moravec et al. 2008, Moravec and Yooyen 2011). However, the study of the exact shape of deirids in Rhabdochona usually requires SEM examination, but this method has not yet been used for many species.

The non-bifurcated deirids with rounded distal tips, the character of anterior prostomal teeth, absence of basal teeth, a slender female tail and non-filamented eggs of $R$. angusticaudata sp. n. are also found in two species of Rhabdochona that are specific parasites of freshwater eels: Rhabdochona anguillae Spaul, 1927 infecting A. anguilla in Europe and Rhabdochona keralaensis Moravec, Sheeba et Kumar, 2012 in Anguilla bengalensis (Gray) in India (Spaul 1927, Moravec et al. 2012b). Of these, R. keralaensis markedly differs from the new species in the size of body (body length of male and female 12.5-17.1 and 22.3-27.8 mm, respectively, vs $8.4-13.6 \mathrm{~mm}$ and $19.1 \mathrm{~mm})$, length of the left spicule (585-636 $\mu \mathrm{m}$ vs 300-384 $\mu \mathrm{m})$, more numerous pairs of subventral preanal papillae (11-13 vs 9), presence (vs absence) of the bifurcated cuticular membrane forming a distinct dorsal outgrowth on the distal tip of the left spicule and a somewhat different arrangement of anterior prostomal teeth.

Rhabdochona anguillae, as redescribed by Moravec (1975) and Saraiva and Moravec (1998), differs from the new species mainly in the lengths of spicules (left and 

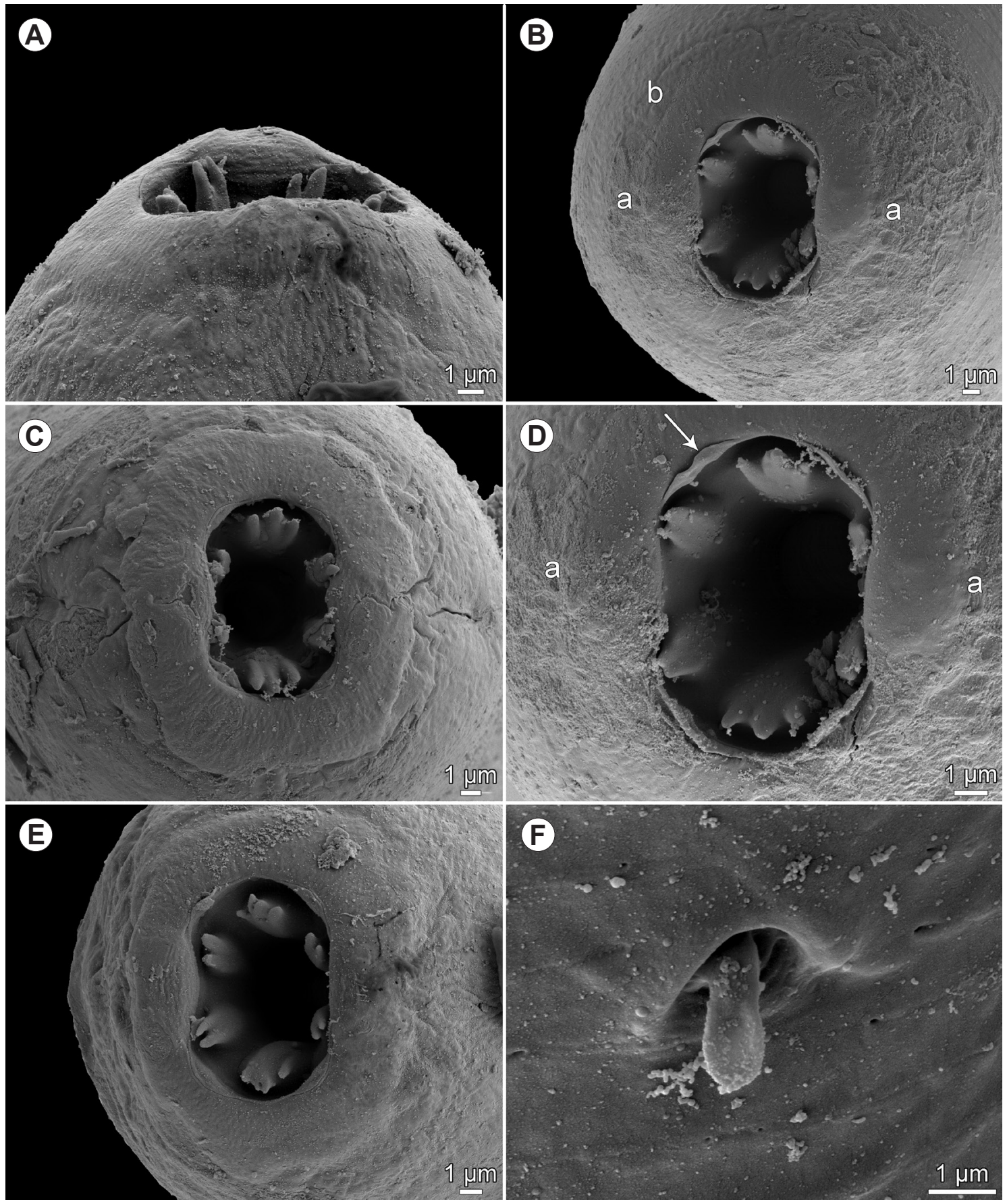

Fig. 9. Rhabdochona angusticaudata sp. n. from Anguilla japonica Temminck et Schlegel, scanning electron micrographs. A-cephalic end of male, lateral view; B - cephalic end of female, apical view; $\mathbf{C}$ - cephalic end of male, apical view; $\mathbf{D}$ - mouth region of female, apical view (arrow indicates sublabium); $\mathbf{E}$ - cephalic end of male (another specimen) with more numerous (16) anterior teeth, apical view; F - deirid. Abbreviations: a - amphid; b - cephalic papilla.

right spicule 460-660 and 130-150 $\mu \mathrm{m}$ long, respectively, vs 300-384 and $81-87 \mu \mathrm{m})$, in the relative length of shaft of the left spicule representing 56-60\% (vs 48\%) of the total spicule length, the dorsal barb on the right spicule is indistinct ( $v s$ right spicule with a conspicuous dorsal barb) and its fully developed eggs are larger (41-54 × 25-30 $\mu \mathrm{m}$ vs $39-42 \times 21-24 \mu \mathrm{m})$.

An inadequately described species, Rhabdochona minjiangensis Wang, 1976, was reported from Anguilla japonica in China (see PRLFTU 1976, Peng et al. 2011). Although it parasitises the same host species as $R$. angusticauda- ta sp. n., it can be easily distinguished from it by the length of the left spicule $(640-700 \mu \mathrm{m} v s$ 300-384 $\mu \mathrm{m})$, the absence ( $v s$ presence) of a dorsal barb on the right spicule and by more numerous (11 vs 9) pairs of subventral preanal papillae. In these features, $R$. minjiangensis is more similar to $R$. anguillae and $R$. keralaensis. Unfortunately, some taxonomically important morphological features, such as the shape of deirids or the detailed structure of the left spicule, were not provided in the description of $R$. minjiangensis. Moreover, the number of reported anterior prostomal teeth (4 pairs) is probably misleading, because these were not 

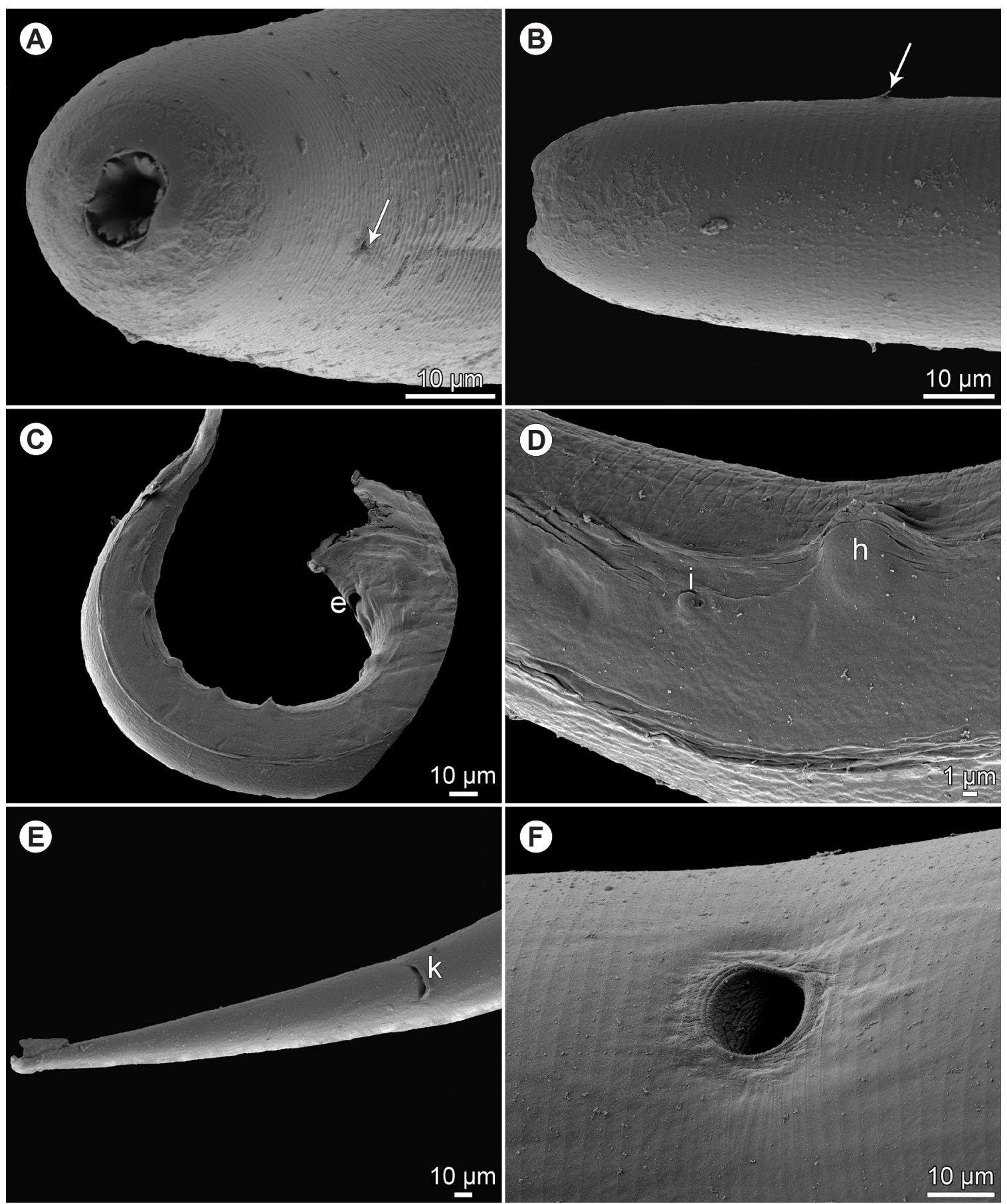

Fig. 10. Rhabdochona angusticaudata sp. n. from Anguilla japonica Temminck et Schlegel, scanning electron micrographs. A, B - anterior end of female body, sublateral and dorsoventral views (arrow indicates deirid); $\mathbf{C}$ - tail of male, lateral view; D - region of male tail with last postanal papilla and phasmid, lateral view; $\mathbf{E}$ - tail of gravid female, ventral view; $\mathbf{F}$ - vulva of gravid female, ventral view. Abbreviations: $\mathrm{e}$ - cloacal aperture; $\mathrm{h}$ - caudal papilla of last postanal pair; $\mathrm{i}$ - phasmid; $\mathrm{k}$ - anus.

studied in apical view, and lateral preanal and postanal papillae were apparently overlooked. Therefore, a redescription of this species based on LM and SEM examinations is needed.

To date, six valid species of Rhabdochona have been reported from fishes in Japan: Rhabdochona coronacauda Belous, 1965, Rhabdochona denudata honshuensis Moravec et Nagasawa, 1989, Rhabdochona japonica Moravec, 1975, Rhabdochona oncorhynchi (Fujita, 1921), Rhabdochona tridentigeris Yamaguti, 1941 and Rhabdo- chona zacconis Yamaguti, 1935 (see Nagasawa 2017). Consequently, $R$. angusticaudata $\mathrm{sp}$. $\mathrm{n}$. is the seventh species of this genus known to occur in Japan. By the general morphology including the length of the left spicule, the new species resembles $R$. denudata honshuensis, a parasite of cyprinids, but these species can be easily distinguished from each other by the shape of deirids, which are simple in $R$. angusticaudata sp. $\mathrm{n}$. and bifurcate in $R$. denudata honshuensis. 

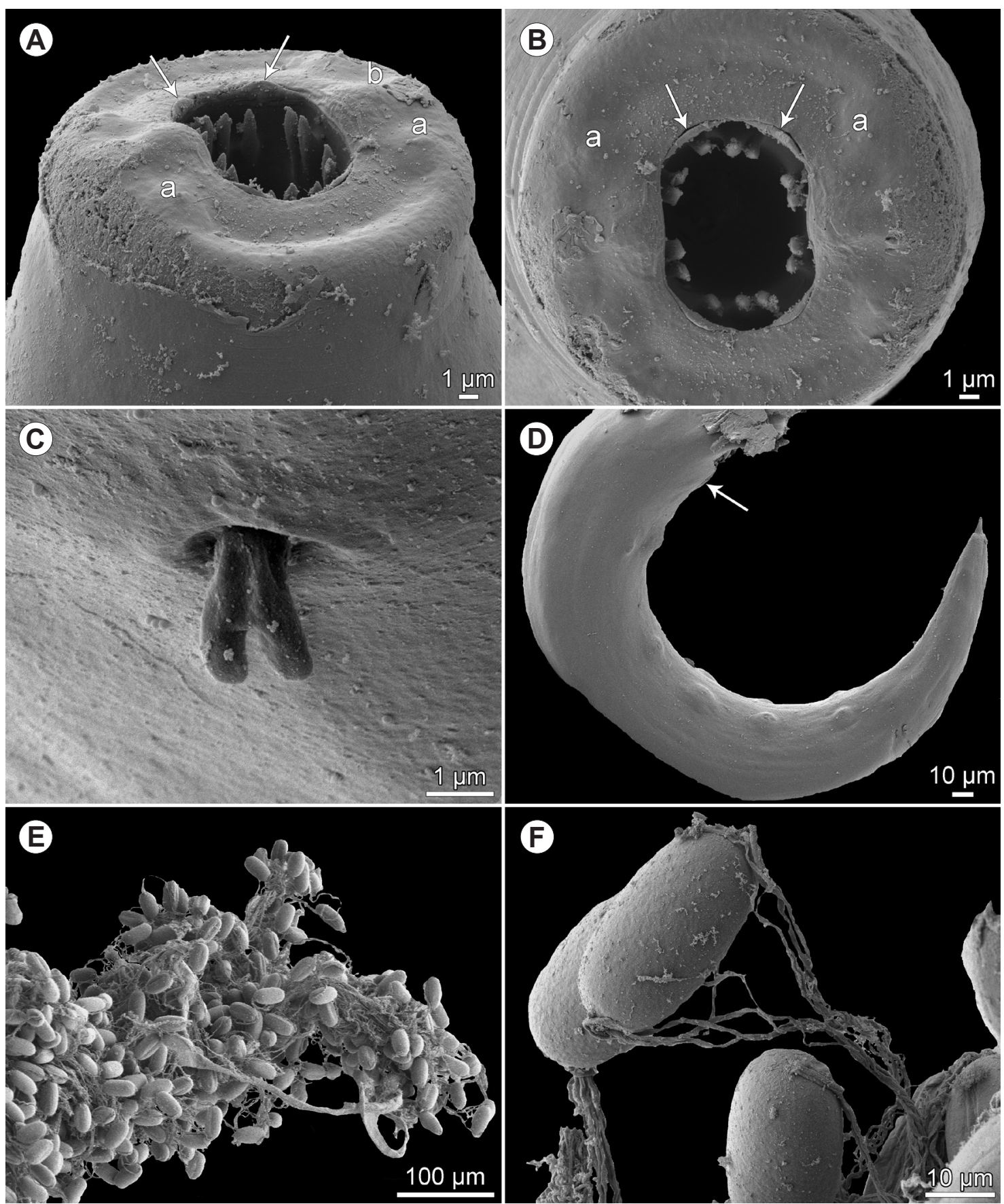

Fig. 11. Rhabdochona zacconis Yamaguti, 1935 from Tribolodon hakonensis (Günther), scanning electron micrographs. A, B - cephalic end of male, subapical and apical views, respectively (arrows indicate sublabia); C - deirid; D - tail of male, lateral view (arrow indicates cloaca); $\mathbf{E}$ - eggs dissected out from uterus; $\mathbf{F}$ - eggs with polar filaments. Abbreviations: a - cephalic papilla; $b$ - amphid.

In this study, several individuals of $A$. japonica from the brackish-water area near the mouth of the Renjoji River were found to be infected by $R$. angusticaudata sp. n. (see "Total prevalence and intensity"), which, however, does not indicate that the nematode is a brackish-water parasite. Like other members of the genus, $R$. angusticaudata sp. n. is a freshwater parasite and considered to infect $A$. japonica in the freshwater environment (e.g. middle-reaches of rivers). Some infected eels may have moved downstream to the brackish-water region.
Rhabdochona zacconis Yamaguti, 1935

Fig. 11

Syn.: Rhabdochona marinum Roytman, 1963.

Host: Big-scaled redfin, Tribolodon hakonensis (Cyprinidae, Cypriniformes).

Site of infection: Intestine.

Locality: Takahara River (a tributary of the Jinzu River), Hida, Gifu Prefecture, Honshu, Japan (collected 1 June 2009).

Prevalence and intensity: 13\% (3 fish infected, 16.0-19.4 $\mathrm{cm}$ TL/23 fish examined, 14.0-21.8 cm TL); 1-5 (mean 2) nematodes per fish.

Deposition of voucher specimens: IPCAS N-38. 
Remarks. The morphology of the present specimens is in full agreement with the redescription of $R$. zacconis provided by Moravec (1975) and Moravec et al. (1981), based on LM examination of specimens from the same host species (T. hakonensis) in Japan. Therefore, we refrain from describing these nematodes. However, the SEM study, used for the first time in this species, made it possible to confirm some features (e.g. cephalic papillae, amphids, arrangement of anterior prostomal teeth, presence of sublabia, shape of deirids, distribution of genital papillae) that are not easily visible using LM (Fig. 11).

Rhabdochona zacconis is known to be distributed in Japan, eastern Russia and western Canada, parasitising cypriniform fishes of the genera Catostomus Lesueur (Catostomidae), Tribolodon Sauvage and Zacco Jordan et Evermann (both Cyprinidae) (Moravec 1975, Moravec et al. 1981, Arai and Mudry 1983, Arai and Smith 2016). In Japan, this parasite was previously recorded by Yamaguti (1935) from Zacco platypus (Temminck et Schlegel) in Nagano Prefecture, Honshu, by Moravec et al. (1981) from T. hakonensis and Z. platypus in Hokkaido (Lakes Akan and Shikotsu [reported erroneously as Chitose, see Nagasawa 2017] and Chihase River) and Honshu (Lake Biwa) (see also Moravec 1975), by Moravec and Nagasawa (1989) from T. hakonensis from several localities in Hokkaido and Honshu, and by Moravec et al. (1998) from T. hakonensis in the Okitsu River, Shizuoka Prefecture, Honshu, where they studied the seasonal maturation cycle of $R$. zacconis in this host. This parasite was recorded from eastern Russia (Sea of Japan, Putiyatin Island) and reported by Russian authors as Rhabdochona denudata (Dujardin, 1845) or as $R$. marinum from Tribolodon brandtii (Dybowski) (see Moravec 1975). Rhabdochona zacconis was also reported from Catostomus macrocheilus Girard in British Columbia, western Canada (Arai and Mudry 1983, Arai and Smith 2016).

\section{Cystidicolidae Skryabin, 1946}

\section{Ascarophis arctica Polyanskiy, 1952}

Figs. 12-14

Description. Small, whitish nematodes. Cuticle thick, with fine transverse striations (Figs. 13B,C, 14D). Cephalic end rounded, with two conspicuous conical pseudolabial terminal protrusions (Figs.12A-E, 13A-C). Oral aperture oval, with lateral extensions. Four submedian labia and 4 submedian flap-like sublabia well developed. Lateral pseudolabia well developed, each provided with conspicuous terminal protrusion; in apical view, flat inner parts of pseudolabia partly cover mouth and are distinctly dorsoventrally expanded, forming 2 (1 dorsolateral and 1 ventrolateral) extensions on each; inner margins of both pseudolabia dorsoventrally straight, parallel to each other (Figs. 12F, 13A-D). Four elongate submedian cephalic papillae and pair of lateral amphids present (Figs. 12F, 13A-C). Vestibule (stoma) long, cylindrical, with small funnel-shaped prostom in lateral view (Fig. 12A-E). Glandular oesophagus in female 6-8 times longer than muscular; both parts of oesophagus distinctly separated from each other (Fig. 12A). Nerve ring encircles muscular oesophagus ap- proximately at border of its first and second thirds; excretory pore located somewhat posterior to level of nerve ring; deirids very small, bifurcate, situated somewhat posterior to end of vestibule (Figs. 12A-C,E, G, 13F).

Male (1 specimen with missing anterior part of body). Length of body fragment 3.56, maximum width 51. Incomplete glandular oesophagus 653 long, maximum width 45. Posterior end of body ventrally curved, provided with narrow caudal alae. Preanal papillae: 4 pairs of subventral pedunculate papillae present, of which first and second and third and fourth are shifted in relation to each other, alternating along margins of tail (Figs. 12I,H, 14A-D). Postanal papillae: 6 pairs present, including 5 pairs of pedunculate subventral papillae and 1 pair of minute ventral sessile papillae located slightly posterior to level of last pair of subventrals (Figs. 12I, 14B). Small median ventral caudal protuberance present at tail tip (Fig. 14D). Ventral cuticular ridges (area rugosa) anterior to cloaca weakly developed, consisting of about 7 longitudinal tessellated ornamentations (Fig. 14C,D). Large (left) spicule 681 long, with pointed distal tip; its shaft 279 long, forming $41 \%$ of overall length of spicule (Figs. 12I,H, 13G). Small (right) spicule boat-shaped, 81 long, with rounded distal end (Fig. 12I,H). Length ratio of spicules 1 : 8.4. Tail conical, 84 long, with rounded tip (Fig. 14A,B,D).

Female (6 gravid specimens with mature eggs). Length of body 8.3-10.9 mm, maximum width 81-105. Height of cephalic protrusions 3. Vestibule including prostom 90-105 long; prostom 12 long, 12-15 wide. Length of muscular oesophagus 219-264, maximum width 18-27; length of glandular oesophagus $1.22-1.89 \mathrm{~mm}$, maximum width 42-57; length ratio of muscular and glandular parts of oesophagus 1 : 5.6-7.6. Length of entire oesophagus and vestibule represents $17-22 \%$ of total body length. Nerve ring, excretory pore and deirids 162-198, 207-300 and 129-135, respectively, from anterior extremity. Vulva somewhat postequatorial, situated 5.07-6.09 $\mathrm{mm}$ from anterior end of body, at 56-69\% of body length; vulval lips not elevated. Vagina directed posteriorly from vulva. Amphidelphic. Uterus filled with numerous eggs. Mature eggs (containing larvae) oval, thick-walled, size 48-54 $\times$ 24-27; thickness of egg wall 4-5. Each pole of egg mostly with small knob provided with 2-5 thread-like filaments; knob on 1 pole somewhat larger than that on opposite pole, usually bearing 0-3 short, fine filaments and 2 thicker and longer filaments; filaments growing up from smaller knob relatively short and fine, 2-3 in number (Figs. 12L, 14E,F); exceptionally knob and filaments present only on 1 pole of larvated egg (Fig. 14G). Tail conical, short, 39-57 long, with 2 lateral papilla-like phasmids near its tip, and a distinct small terminal knob-like projection (Figs. 12K, 13E).

Host: Three-spined stickleback, Gasterosteus aculeatus Linnaeus (Gasterosteidae, Gasterosteiformes).

Site of infection: Stomach.

Locality: Nishittapu River, Tomakomai, Hokkaido, Japan (collected 16 June 1996 and 19 June 2009).

Total prevalence and intensity: $25 \%$ (3 fish infected/12 fish examined); 1-6 (mean 3) nematodes per fish. 1996: 1 fish in- 

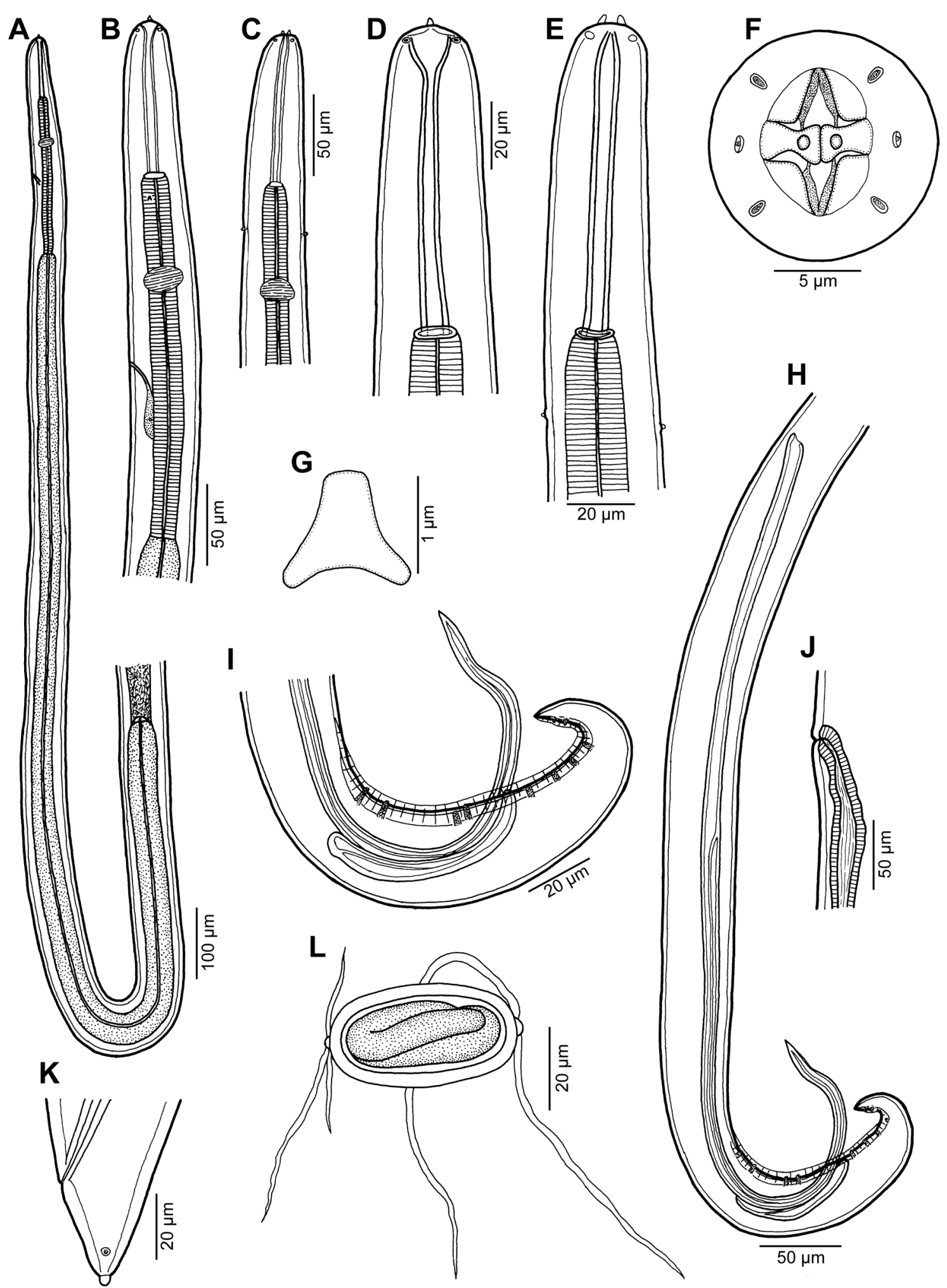

Fig. 12. Ascarophis arctica Polyanskiy, 1952 from Gasterosteus aculeatus Linnaeus. A - anterior end of female body, lateral view; $\mathbf{B}, \mathbf{C}$ - anterior end of female, lateral and dorsoventral views, respectively; $\mathbf{D}, \mathbf{E}$ - vestibule of female, lateral and dorsoventral views, respectively; F - cephalic end of female, apical view; $\mathbf{G}$ - deirid; H - posterior end of male, lateral view; $\mathbf{I}$ - caudal end of male, lateral view; $\mathbf{J}$ - vulva, lateral view; $\mathbf{K}$ - tail of female, lateral view; $\mathbf{L}$ - egg.

fected, fish size not measured/1 fish examined; 3 nematodes. 2009: $18 \%$ ( 2 fish infected, 7.1 and $8.2 \mathrm{~cm}$ TL/11 fish examined, 7.9-9.1 cm TL); 1 and 6 nematodes.

Deposition of voucher specimens: IPCAS N-1153.
Remarks. The general morphology of the present nematodes from $G$. aculeatus indicates that they belong to the nominotypical subgenus Ascarophis van Beneden, 1870 (see Moravec and Justine 2009) of the cystidicolid genus 

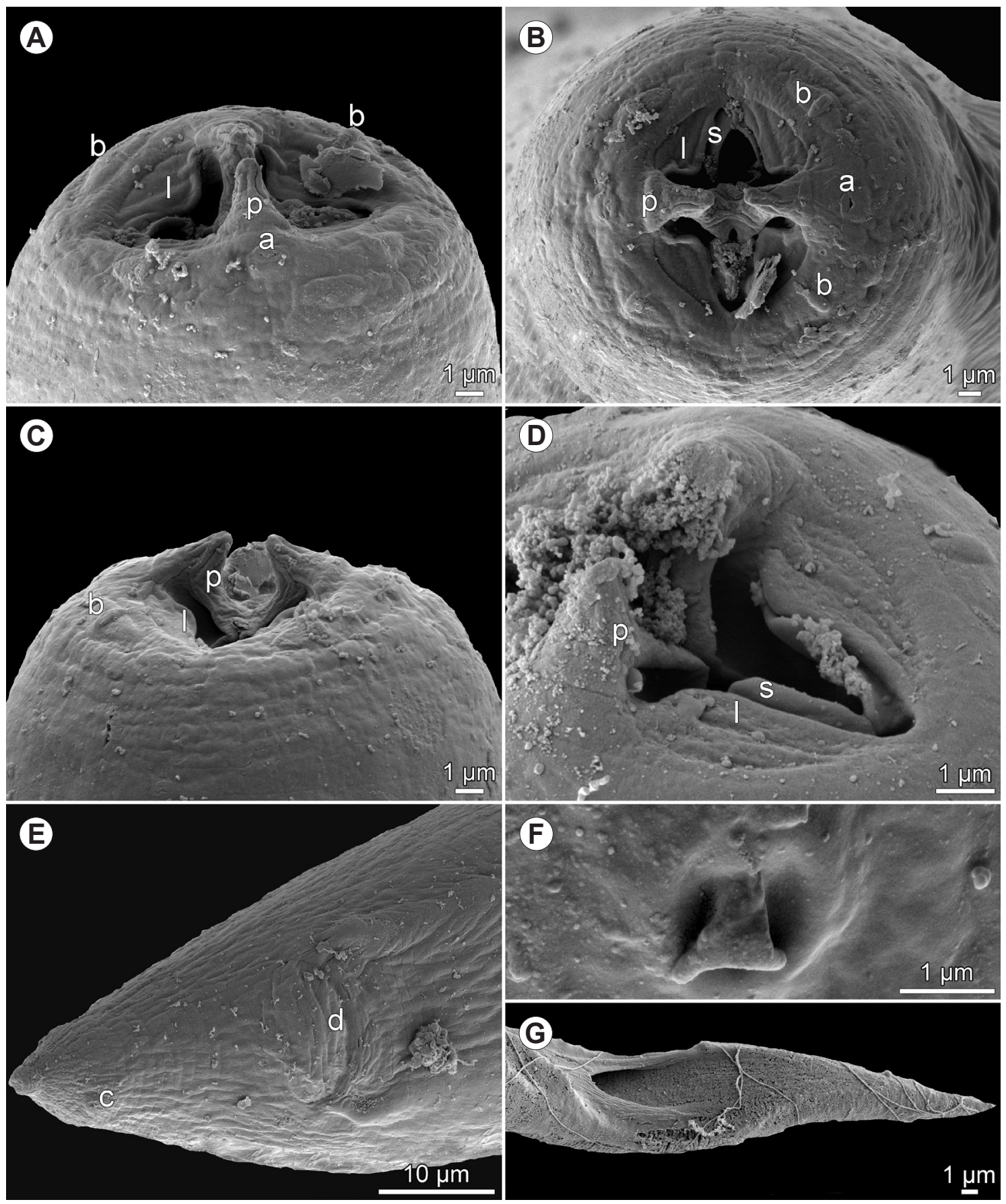

Fig. 13. Ascarophis arctica Polyanskiy, 1952 from Gasterosteus aculeatus Linnaeus, scanning electron micrographs. A-C - cephalic end of female, lateral, apical and dorsoventral views, respectively; D - region of female mouth (another specimen), sublateral view; $\mathbf{E}$ - tail of female, ventral view; F - deirid; $\mathbf{G}$ - distal end of left spicule, ventral view. Abbreviations: a - amphid; b - cephalic papilla $\mathrm{c}$ - phasmid; $\mathrm{d}$ - anus; 1 - labium; $\mathrm{p}$ - pseudolabium with anterior tooth-like projection; $\mathrm{s}$ - sublabium.

Ascarophis van Beneden, 1870, as defined by Ko (1986). At present, 41 species of this genus are considered to be valid (Moravec et al. 2018).

Only the following seven species of the genus Ascarophis have filamented eggs and a large (left) spicule length similar to that of the species under study $(681 \mu \mathrm{m})$ : A. arctica (left spicule 500-980 $\mu \mathrm{m}$ long), Ascarophis draconi Muñoz et George-Nascimento, 2007 (482-640 $\mu \mathrm{m})$, Ascarophis litoralica Zhukov, 1960 (590-670 $\mu \mathrm{m})$, Ascarophis marina (Szidat, 1961) (405-600 $\mu \mathrm{m})$, Ascarophis morrhuae van Beneden, 1870 (500-790 $\mu \mathrm{m})$, Ascarophis maulensis (Muñoz, González et George-Nascimento, 2004) (550-690 $\mu \mathrm{m})$ and Ascarophis richeri Moravec et Justine,

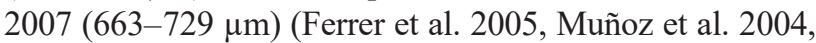
Moravec and Justine 2007, Muñoz and George-Nascimento 2007). Of these, however, A. marina, A. maulensis and A. richeri have a different structure of the mouth and they belong to the subgenus Similascarophis Muñoz, González et George-Nascimento, 2004 (see Moravec and Justine 2007). The remaining four species are representatives of the subgenus Ascarophis, as are the present specimens from G. aculeatus. 

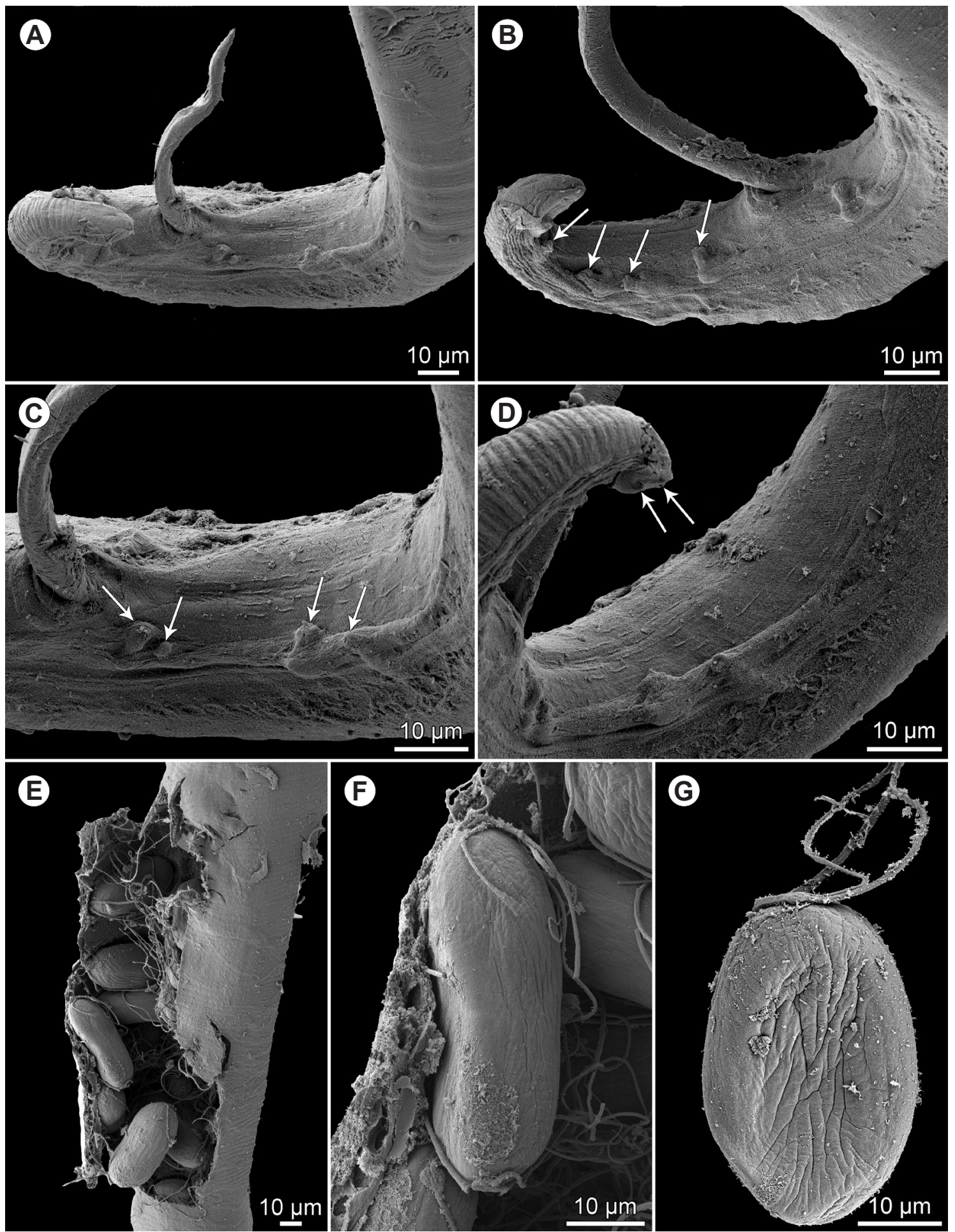

Fig. 14. Ascarophis arctica Polyanskiy, 1952 from Gasterosteus aculeatus Linnaeus, scanning electron micrographs. A - posterior end of male, ventral view; B - tail of male, subventral view (arrows indicate postanal papillae); $\mathbf{C}$ - precloacal region, subventral view (arrows indicate preanal papillae; note weakly-developed ventral precloacal ridges); D - posterior end of male, sublateral view (arrows indicate two posteriormost pairs of postanal papillae; note ventral precloacal ridges); $\mathbf{E}$ - broken female body with eggs; $\mathbf{F}$ - egg with filaments on both poles; $\mathbf{G}$ - egg with filaments only on one pole.

However, A. draconi has much longer males and females (males 9.9-13.3 mm, females 20.9-28.6 mm) and the eggs have two filaments on each pole; $A$. litoralica has also eggs with only two filaments on each pole, whereas its body measurements are similar to those of the present nematodes from Japan. Both $A$. draconi and A. litoralica were described from the Pacific Ocean (off Chile and in the South-Kurile shallow waters, respectively) (Zhukov 1960, Muñoz and George-Nasciento 2007); the latter species has not yet been studied by SEM.

Two other species, A. arctica and A. morrhuae, were reported from different marine fishes (mostly Gadiformes 
and Scorpaeniformes) in the Atlantic and Arctic Oceans, being separated from each other mainly by the number and arrangement of egg filaments (two filaments only on one egg pole in A. morrhuae and several filaments on both egg poles in A. arctica) (Polyanskiy 1952, Appy 1981, Ko 1986, Fagerholm and Berland 1988). However, as confirmed in this paper, the number and character of egg filaments may be rather variable within the same species of Ascarophis and, therefore, should not be overestimated as a taxonomic feature.

The original description of $A$. morrhuae by van Beneden (1870) was poor and, as pointed out by Zhukov (1960), apparently more congeneric species were included under this name from different hosts by subsequent authors. Therefore, a detailed redescription of this type species of Ascarophis, based on specimens newly collected from the type host and the type locality (off the coast of Belgium) is needed.

The general morphology of the present nematodes from $G$. aculeatus shows that these can be assigned, according to present criteria, to $A$. arctica, even though, as compared with the descriptions of $A$. arctica from other fish hosts (Polyanskiy 1952, Appy 1981, Fagerholm and Berland 1988), the filaments on both poles of larvated eggs of these nematodes are less numerous (2-5 vs up to18 on each pole according to Fagerholm and Berland 1988) and the knob from which filaments are growing is distictly smaller on one egg pole as compared to that on the opposite pole, and ventral precloacal ridges in the male are poorly developed ( $v s$ well developed). In addition to the presence of several filaments on each pole in the majority of larvated eggs, these nematodes possess flap-like sublabia (Figs.12F, 13A-D), typical of A. arctica, as visible on SEM micrographs of Appy (1981) and Fagerholm and Berland (1988). Specimens of $A$. morrhuae from its type host (Gadus morhua Linnaeus) have not yet been studied by SEM, but those from Trisopterus capellanus (Lacépède) had distinctly bi-lobed sublabia (see fig. 75 of Ko 1986), although specimens from Agonus cataphractus (Linnaeus), also considered by Ko (1986) to be $A$. morrhuae, possessed flap-like sublabia.

Ascarophis arctica was originally described from the stomach of the eelpout Zoarces viviparus (Linnaeus) (Zoarcidae, Perciformes) in the Barents Sea (Polyanskiy 1952) and subsequently it was also reported from different marine, mostly gadiform and scorpaeniform fishes in the North Atlantic region (Canada, Europe) (Appy 1981, Fagerholm and Berland 1988). The only record of A. arctica from G. aculeatus is that of Levsen (1992), who, without giving any morphological data, listed this nematode as a parasite of this fish species in western Norway (Bergen area). Therefore, the present finding of this parasite in Japan represents the first record of $A$. arctica in the region of the Pacific Ocean. Its host, G. aculeatus, is distributed in circumarctic and temperate regions of Northern Hemisphere (Froese and Pauly 2018). Hanek and Threlfall (1970) reported a different species of Ascarophis, A. morrhuae, as a common parasite of G. aculeatus in Newfound- land and Labrador, Canada, but no morphological data were provided.

The Nishittapu River population of G. aculeatus is composed of both anadromous and fluvial indviduals (Higuchi and Goto 1994, 1996; they reported this river erroneously as the Nishikitappu River): the former individuals migrate to the sea for feeding and return to the river for spawning. The infected fish found in this study are considered to have become parasitised by $A$. arctica at sea.

According to Nagasawa (2016), to date the only record of a species of Ascarophis from Japanese inland fishes is that of Margolis (1957), who reported Ascarophis sp. from the pink salmon Oncorhynchus gorbuscha (Walbaum). Several years ago, we examined two damaged males of Ascarophis from the stomach of the same host species (O. gorbuscha) in the Shikiu River, Hokkaido (collected 14 August 1981), provided by Dr. Shigehiko Urawa (Hokkaido National Fisheries Research Institute, Sapporo, unpublished). Since their left spicule was much shorter (264 and $288 \mu \mathrm{m}$ ) than that of $A$. arctica, they evidently belonged to a different species. However, having no conspecific females, their identification to species was impossible. Zhukov (1960) reported seven Ascarophis spp. from marine fishes (not Salmonidae) in the Sea of Japan and South-Kurile shallow waters, of which Ascarophis japonicus Zhukov, 1960 and Ascarophis pacificus Zhukov, 1960 have the left spicule length similar to that of Ascarophis sp. parasitising $O$. gorbuscha. More attention should be paid to Ascarophis sp. from salmon in Japan.

\section{Dioctophymatidae Castellani et Chalmers, 1910}

\section{Eustrongylides sp. fourth-stage larvae}

Fig. 15

Hosts: Amur catfish, Silurus asotus (Siluridae, Siluriformes), and snakehead, Channa argus (Channidae, Perciformes).

Sites of infection: Mesentery (S. asotus), and body cavity and mouth cavity (C. argus).

Localities: Kurose River, Higashi-Hiroshima, Hiroshima Prefecture ( $S$. asotus) (no data on sampling date), Kamo River (a tributary of the Ashida River), Fukuyama, Hiroshima Prefecture (collected 26 November 2008) and Lake Shinji, Matsue, Shimane Prefecture (collected 16 September 2009) (both C. argus), all Honshu, Japan.

Prevalence and intensity: S. asotus: no data on prevalence; 17 nematodes. C. argus: Kamo R.: 1 fish infected, $61.5 \mathrm{~cm}$ TL/1 fish examined; 2 nematodes; and L. Shinji: 1 fish infected, $90.0 \mathrm{~cm} \mathrm{TL} / 1$ fish examined; 1 nematode.

Deposition of voucher specimens: IPCAS N-76.

Remarks. Larvae of Eustrongylides Jägerskiöld, 1909 from fishes and some other aquatic vertebrates, serving as paratenic hosts, are unidentifiable to species by morphological features (Measures 1988). Adults of this genus are parasites of the proventriculus of fish-eating birds. Eustrongylides larvae in Japan have already been reported from Rhinogobius similis Gill, Rhinogobius sp. (both Gobiidae) and Channa argus (Channidae) (Yamaguti 1941, Shimazu et al. 2000). Currently, based on molecular and morphological studies, a pinkish worm from the abdominal wall 

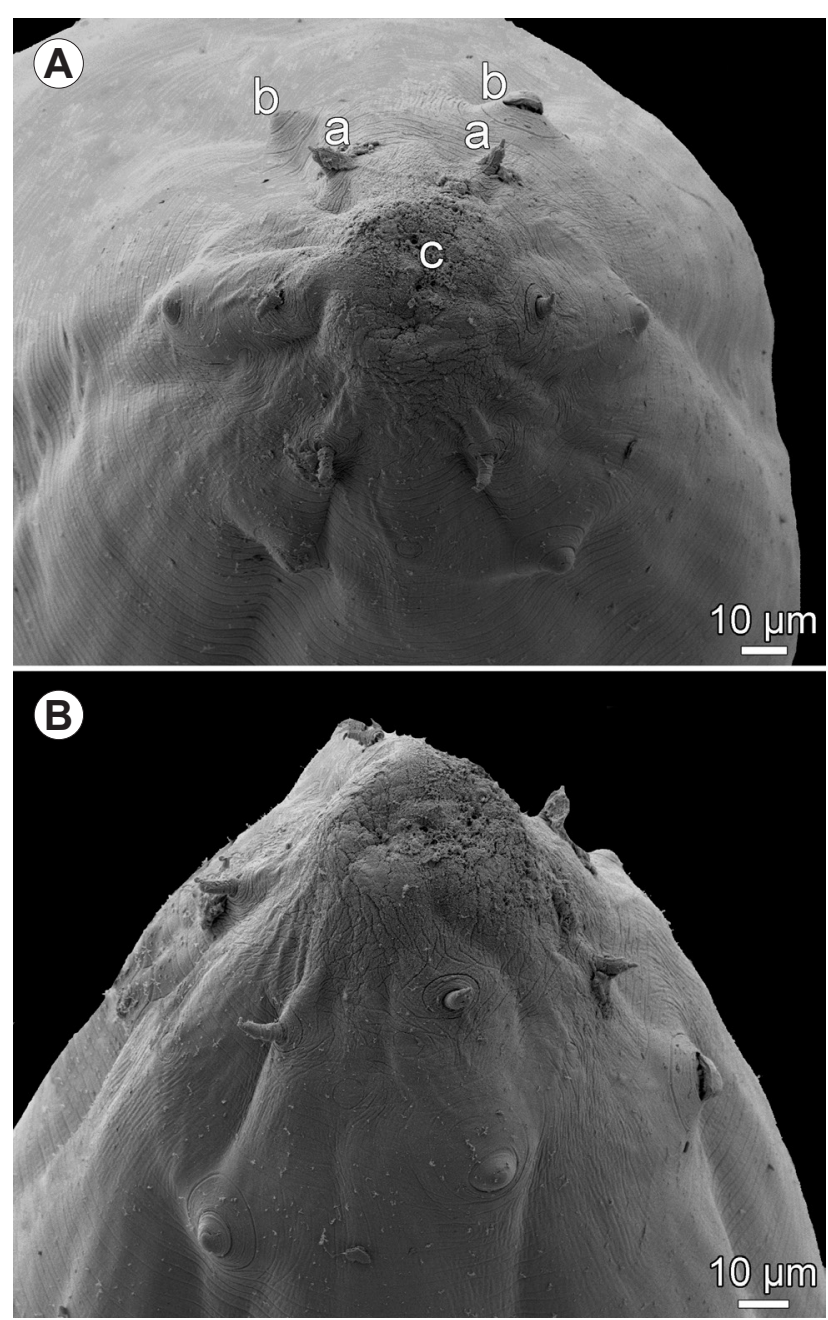

Fig. 15. Eustrongylides sp. larva from Channa argus (Cantor), scanning electron micrographs of cephalic end. A - apical view; B - sublateral view. Abbreviations: a - cephalic papillae of inner circle; $b$ - cephalic papillae of outer circle; $\mathrm{c}$ - mouth opening.

of the Japanese smelt Hypomesus nipponensis McAllister (reported as $H$. transpacificus nipponensis) (Osmeridae) caught in Lake Biwa, Shiga Prefecture, Honshu, was identified as a larva of Eustrongylides ignotus Jägerskiöld, 1909 (see Abe 2011). In this study, one specimen of Eustrongylides sp. was found in the mouth cavity of C. argus, which probably resulted from the migration from the body cavity after the fish was dead.

\section{DISCUSSION}

As mentioned above, the fauna of Japan is of particular interest from the viewpoint of zoogeography, which also concerns nematode parasites of freshwater fishes. According to the checklist of the parasitic nematodes of freshwater fishes of Japan (Nagasawa 2016, 2017), 52 nominal species and several unidentified species belonging to 17 families were recorded in Japan during the 111 years (1905-2016) of ichthyoparasitological investigations in the country. Of these, 30 species were nematodes maturing in fishes, i.e., for which fishes serve as definitive hosts. The present study increases the number of adult nematode species parasitising freshwater fishes in Japan to 33.

Of special interest are the first records of two nematode species parasitic in the Japanese eel Anguilla japonica, i.e., Paraquimperia sp. and Rhabdochona angusticaudata sp. n., of which at least the latter may be endemic to Japan. Although some fish nematodes occurring in Japan are distributed throughout the Palaearctic Region or only in its eastern part, representatives of two genera, Ezonema Boyce, 1971 and Mexiconema Moravec, Vidal et Salgado-Maldonado, 1992, seem to be endemic to Japan, as well as, for example, Rhabdochona japonica, a parasite of the Japanese endemic catfish Liobagrus reini Hilgendorf (see Moravec and Nagasawa 1998). However, it can be expected that additional species of nematodes will be recorded from freshwater fishes in Japan in future.

Acknowledgements. We thank Toshihiko Saito (National Hokkaido Fisheries Research Institute, Sapporo), Kouki Mizuno (Ehime Prefectural Uwajima Fishery High School, Uwajima), Hidenori Yoshigou (Chugai Technos Co. Ltd., Hiroshima) and Yukinori Tokuda (Takahara Fisheries Cooperative, Hida) for their help with fish sampling. Thanks are also due to the Laboratory of Electron Microscopy, Institute of Parasitology, Biology Centre CAS, institution supported by the MEYS CR (LM2015062 Czech-BioImaging) for their support with obtaining scientific data presented in this paper, and to Blanka Škoríková of the same Institute for help with the illustrations. We are grateful to Liang Li, Hebei Normal University, China for his help with obtaining the article published in a hardly accessible Chinese journal and for the translation of the necessary Chinese text into English. This study was partly supported by the Czech Science Foundation (Grant. No. P505/12G112) and by institutional support (RVO: 60077344, Institute of Parasitology, BC AS CR).

\section{REFERENCES}

AвE N. 2011: Molecular and morphological identification of helminthes found in Japanese smelt, Hypomesus transpacificus nipponensis, with notes on new host records of Eustrongylides ignotus and Raphidascaris gigi. Acta Parasitol. 56: 227-231.

ANDERSON R.C. 1988: Nematode transmission patterns. J. Parasitol. 74: 30-45.

Anderson R.C. (ED.) 2000: Nematode Parasites of Vertebrates. Their Development and Transmission. 2nd Edition. CABI, Wallingford, UK, 672 pp.
Anderson R.C., Chabaud A.G., Willmott S. (Eds.) 2009: Keys to the Nematode Parasites of Vertebrates. Archival volume. CAB International, Wallingford, $480 \mathrm{pp}$.

ANONYMOUs 2002: [The parasite fauna of fishes in an experimental river and its characteristics.] Ann. Rep. Aqua Restoration Res. Center 2001, pp. 206-218. (In Japanese.)

Appy R.G. 1981: Species of Ascarophis van Beneden, 1870 (Nematoda: Cystidicolidae) in North Atlantic fishes. Can. J. Zool. 59: 2193-2205.

Arai H.P., Mudry D.R. 1983: Protozoan and metazoan parasites of fishes from the headwaters of the Parsnip and McGregor Riv- 
er, British Columbia: a study of possible parasite transfaunations. Can. J. Fish. Aquat. Sci. 40: 1676-1684.

Arai H.P., Sмith J.W. 2016: Guide to the parasites of fishes of Canada. Part V: Nematoda. Zootaxa 4185: 1-274.

VAN Beneden P.-J. 1870: Les poissons des côtes de Belgique, leurs parasites et leurs commensaux. Mem. Acad. Roy. Belg. 38 $1-100$.

Cremonte F., Navone G.T., Gosztonyi A.E., Kuba L. 2002: Redescription of Rhabdochona (Rhabdochona) acuminata (Nematoda: Rhabdochonidae) from freshwater fishes from Patagonia (Argentina), the geographical implications. J. Parasitol. 88: 934-941.

Dogel V.A., Aknmerov A.KH. 1959: [Nematodes of fishes of the River Amur.] Acta Hydrobiol. Sin. 3: 272-304. (In Chinese and Russian.)

Fagerholm H.-P., Berland B. 1988: Description of Ascarophis arctica Polyansky, 1952 (Nematoda: Cystidicolidae) in Baltic Sea fishes. Syst. Parasitol. 11: 151-158.

Ferrer E., Aznar F.J., Balbuena J.A., Kostadinova A., Raga J.A., Moravec F. 2005: A new cystidicolid nematode from Mullus surmuletus (Perciformes: Mullidae) from the western Mediterranean. J. Parasitol. 91: 335-344.

Froese R., Pauly D. (Eds.) 2018: FishBase. World Wide Web electronic publication, http://www.fishbase.org, version 03/2018.

Grygier M.J., Hirasawa R. 2011: Parasitic Nematoda. In: O.A. Timoshkin (Ed.), Index of animal species inhabiting Lake Baikal and its catchment area. Volume II. Basins and Channels in the South of East Siberia and North Mongolia. Nauka, Novosibirsk, items 1464 and 1498.

Grygier M.J., Urabe M. 2003: Fish parasites introduced into Lake Biwa from overseas. Umindo (Quarterly Newsletter of the Lake Biwa Museum) 8: 6. (In Japanese.)

Hanek G., Threlfall W. 1970: Parasites of the threespine stickleback (Gasterosteus aculeatus) in Newfoundland and Labrador J. Fish. Res. Bd. Canada 27: 901-907.

Higuchi, M., Gото, A. 1994: [Population structure and process in speciation of three-spined stickleback.] In: A. Goto, K. Tsukamoto, K. Maekawa (Eds.), Freshwaters Fishes Migrating Between Rivers and Sea - Their Life History and Evolution. Tokai University Press, Tokyo, pp. 114-126, 257-259. (In Japanese.)

Higuchi, M., Goto, A. 1996: Genetic evidence supporting the existence of two distinct species in the genus Gasterosteus around Japan. Environ. Biol. Fishes 47: 1-16.

HsÜ H.F. 1933: On some parasitic nematodes collected in China. Parasitology 24: 512-541.

Katahira H., Mizuno K., Nagasawa K. 2011: Host size- and habitat-dependent intensity of Heliconema longissimum (Nematoda: Physalopteridae) in the Japanese eel (Anguilla japonica). J. Parasitol. 97: 994-998.

Katahira H., Nagasawa K. 2015: Heliconema anguillae Yamaguti, 1935, a physalopterid nematode found in Japanese eels: taxonomic resurrection with a note on the third-stage larva from intertidal crabs in western Japan. Folia Parasitol. 62: 028.

KO R.C. 1986: A preliminary review of the genus Ascarophis van Beneden, 1871 (Nematoda: Cystidicolidae) of the gastrointestinal tract of fishes. Occasional Publications, Department of Zoology, University of Hong Kong, 54 pp.

Ky H. 1971: [Some species of nematodes from freshwater fishes in North Vietnam.] Parazitologiya 5: 241-250. (In Russian.)

LevSEN A. 1992: Parasites of the three-spined stickleback Gasterosteus aculeatus from Norway, with emphasis on trichodinid ciliates. Fauna, Norsk Zoologisk Forenings Tidssrift, Oslo, 45: 40-48. (In Norwegian with English summary.)

Li L., LiU Y.-Y., LiU B.-C., Zhang L.-P. 2013: Morphological and molecular characterisation of Heliconema hainanensis sp. nov. (Spirurina: Physalopteridae) from congers in the South China Sea, with a key to the species of Heliconema. Mem. Inst. Oswaldo Cruz 108: 41-47.

Machida M., TaKahashi K., MasuUchi S. 1978: Thynnascaris haze n. sp. (Nematoda, Anisakidae) from goby in the Bay of Tokyo. Bull. Natl. Mus. Nat. Sci. Ser. A Zool. 4: 241-244.
MARGOLIS L. 1957: A study of the parasites of sockeye and pink salmon with particular attention to their application in distinguishing between Asiatic and North American stocks of these fish on the high seas - Report of results of examination of 1956 samples. Fish. Res. Bd. Canada, Manuscript Reports (Biol.), 641, 1-24.

Margolis L., Butler T.H. 1954: An unusual and heavy infection of a prawn, Pandalus borealis Krøyer, by a nematode, Contracaecum sp. J. Parasitol. 40: 649-655.

Measures L.N. 1988: Revision of the genus Eustrongylides Jägerskiöld, 1909 (Nematoda: Dioctophymatoidea) of piscivorous birds. Can. J. Zool. 66: 885-895.

Moravec F. 1975: Reconstruction of the Nematode Genus Rhabdochona Railliet, 1916 with a Review of the Species Parasitic in Fishes of Europe and Asia. Studie ČSAV No. 8. Academia, Prague, $104 \mathrm{pp}$.

Moravec F. 2010: Some aspects of the taxonomy, biology, possible evolution and biogeography of nematodes of the spirurine genus Rhabdochona Railliet, 1916 (Rhabdochonidae, Thelazioidea). Acta Parasitol. 55: 144-160.

Moravec F. 2013: Parasitic Nematodes of Freshwater Fishes of Europe. Revised Second edition. Academia, Prague, $601 \mathrm{pp}$.

Moravec F., Boomker J., Taraschewski H. 2000: Paraquimperia africana $\mathrm{n}$. sp. (Nematoda: Quimperiidae), a new intestinal parasite of the eel Anguilla mossambica Peters, in South Africa. J. Parasitol. 86: 113-117.

MoraVeC F., JiRKU M. 2014: Rhabdochona spp. (Nematoda: Rhabdochonidae) from fishes in the Central African Republic, including three new species. Folia Parasitol. 61: 157-172.

Moravec F., Justine J.-L. 2007: A new species of Ascarophis (Nematoda, Cystidicolidae) from the stomach of the marine scorpaeniform fish Hoplichthys citrinus from a seamount off the Chesterfield Islands, New Caledonia. Acta Parasitol. 52: 238-246.

Moravec F., Justine J.-L. 2009: Two cystidicolids (Nematoda, Cystidicolidae) from marine fishes off New Caledonia. Acta Parasitol. 54: 341-349.

Moravec F., Margolis L., Boyce N.P. 1981: Some nematodes of the genus Rhabdochona (Spirurida) from fishes of Japan. Acta Soc. Zool. Bohemoslov. 45: 277-290.

Moravec F., Nagasawa K. 1989: Observations on some nematodes parasitic in Japanese freshwater fishes. Folia Parasitol. 36: $127-141$.

Moravec F., Nagasawa K. 1998: Helminth parasites of the rare endemic catfish, Liobagrus reini, in Japan. Folia Parasitol. 45: 283-294.

Moravec F., Nagasawa K., Madinabeitia I. 2010: A new species of Capillaria (Nematoda: Capillariidae) from the intestine of the marine fish Acanthopagrus schlegelii schlegelii (Sparidae) from Japan. J. Parasitol. 96: 771-774.

Moravec F., Nagasawa K., Nohara K. 2012a: Two species of philometrid nematodes (Philometridae) from marine fishes off Japan, including Philometroides branchiostegi $\mathrm{sp}$. n. from Branchiostegus japonicus (Malacanthidae). Folia Parasitol. 59: 71-78.

Moravec F., Nagasawa K., Urushibara Y. 1998: Observations on the seasonal maturation of the nematode Rhabdochona zacconis in Japanese dace, Tribolodon hakonensis, of the Okitsu River, Japan. Acta Soc. Zool. Bohemoslov. 62: 45-50.

Moravec F., Nie P., Wang G. 2003: Some nematodes of fishes from central China, with the redescription of Procamallanus (Spirocamallanus) fulvidraconis (Camallanidae). Folia Parasitol. 50: 220-230.

Moravec F., Řína M., Kuchta R. 2008: Two new nematode species, Paragendria papuanensis sp. n. (Seuratoidea) and Rhabdochona papuanensis sp. n. (Thelazioidea), from freshwater fishes in Papua New Guinea. Folia Parasitol. 55: 127-135.

Moravec F., Sey O. 1988: Nematodes of freshwater fishes from North Vietnam. Part 3. Cosmocercoidea, Seuratoidea, Atractoidea, Heterakoidea and Ascaridoidea. Acta Soc. Zool. Bohemoslov. 52: 250-265. 
Moravec F., Sheeba S., Kumar A.B. 2012b: Rhabdochona (Rhabdochona) keralaensis sp. nov. (Rhabdochonidae) and some other nematodes in the Indian mottled eel Anguilla bengalensis bengalensis from India. Acta Parasitol. 57: 74-82.

Moravec F., Sheeba S., Kumar A.B. 2013a: Observations on nematodes from the Indonesian shortfin eel Anguilla bicolor bicolor McClelland in India, including a revalidation of Heliconema ahiri Karve, 1941 (Physalopteridae). Acta Parasitol. 58: 496-503.

Moravec F., Taraschewski H., Weyl O. L. F. 2013b: Redescription of Heliconema africanum (Linstow, 1899) n. comb. (Nematoda: Physalopteridae), a nematode parasite of freshwater eels (Anguilla spp.) in South Africa. Syst. Parasitol. 85: 263-269.

Moravec F., Yooyen T. 2011: Two new species of Rhabdochona (Nematoda: Rhabdochonidae) from freshwater fishes in Thailand. Folia Parasitol. 58: 224-232.

Moravec F., Yooyen T., Sanprick A. 2018: Two nematode species from freshwater and marine fishes in Thailand, including Ascarophis scatophagi sp. nov. (Cystidicolidae) from Scatophagus argus (Scatophagidae). Acta Parasitol. 63: 89-98.

Muñoz G., George-Nascimento M. 2007: Two new species of Ascarophis (Nematoda: Cystidicolidae) in marine fishes from Chile. J. Parasitol. 93: 1178-1188.

Muñoz G., González M.T., George-Nascimento M. 2004 Similascarophis n. gen. n. spp. (Nematoda: Cystidicolidae) parasitizing marine fishes off the Chilean coast. J. Parasitol. 90: 823-834.

NAGASAWA K. 2016: [A checklist of the parasitic nematodes of freshwater fishes of Japan (1905-2016) - Part 1.] Bull. Hiroshima Univ. Mus. 8: 61-90. (In Japanese with English summary.)

NAGASAWA K. 2017: [A checklist of the parasitic nematodes of freshwater fishes of Japan (1905-2016) - Part 2.] Bull. Hiroshima Univ. Mus. 9: 121-142. (In Japanese with English summary.)

Nagasawa K., Katahira H. 2017: A revised and updated checklist of the parasites of eels (Anguilla spp.) (Anguilliformes: Anguillidae) in Japan (1915-2017). Biosph. Sci. 56: 33-69.

ODENING K. 1976: Conception and terminology of hosts in parasitology. Adv. Parasitol. 14: 1-93.

Ogden C.G. 1969: A revision of the genus Heliconema Travassos, 1919, Physalopteridae (Nematoda). J. Nat. Hist. 3: 423-431.

Parasitology Research Laboratory of Fujian Teachers UNIVERSITY (PRLFTU) 1976: [Investigation of parasites from Anguilla japonica in Fujian Province. I.] J. Fujian Teachers Univ. 1: 103-107. (In Chinese.)

Peng W., Liu S., Wang B. Wei M. 2011: A checklist of parasitic nematodes from marine fishes of China. Syst. Parasitol. 79: 17-40.

Polyanskiy Yu.I. 1952: [Some new and little-known parasitic nematodes from the intestine of marine fishes.] Tr. Zool. Inst. AN SSSR 12: 133-147. (In Russian.)

Ramallo G. 2005: Observations on two Rhabdochona species (Nematoda: Rhabdochonidae) from freshwater fishes in Argen- tina, including description of Rhabdochona fabianae n. sp. J. Parasitol. 91: 415-419.

Saraiva A.M., Moravec F. 1998: Redescription of Rhabdochona anguillae (Nematoda: Rhabdochonidae), a parasite of eel, Anguilla anguilla, in Europe. Folia Parasitol. 45: 233-238.

Shimazu T., Kuramochi T., Araki J., Machida M. 2000: Digenean, cestode, and nematode parasites of freshwater fishes of the Imperial Palace, Tokyo. Mem. Natn. Sci. Mus. Tokyo 35: 211-231.

Spaul E.A. 1927: On a new species of the nematode genus Rhabdochona. Ann. Mag. Nat. Hist. 19: 36-641.

Takahashi K., Masuuchi S., Nakamura T., Ogura M., AriMA T. 1977: [On a nematode from Acanthogobius flavimanus (2).] In: Annual Report of Ecological Survey of Fishes and Shellfishes in the Inner Area of Tokyo Bay (1975). Publ. Tokyo Metropol. Fish. Exper. Station 276: 89-93. (In Japanese.)

Takahashi K., Masuuchi S., Nakamura T., Saito M. 1976. [On a nematode from Acanthogobius flavimanus.] In: Annual Report of Ecological Survey of Fishes and Shellfishes in the Inner Area of Tokyo Bay (1974). Publ. Tokyo Metropol. Fish. Exper. Station No. 267: 42-50. (In Japanese.)

Wang P., ZhaO Y., Chen C. 1978: [On some nematodes from vertebrates in South China.] Fujian Shida Xuebao 2: 75-90. (In Chinese.)

Wu H.S. 1956: Studies on the parasitic nematodes of freshwater fishes in China 1. Acta Hydrobiol. Sin. 2: 99-106 + 3 Plts. (In Chinese with English summary.)

Yamaguti S. 1935: Studies on the helminth fauna of Japan. Part 9. Nematodes of fishes. Jap. J. Zool. 6: 337-386.

Yamaguti S. 1941: Studies on the helminth fauna of Japan. Part 33 Nematodes of fishes, II. Jpn. J. Zool. 9: 343-396 + Pls. IV-VI.

YoshinaGa T. 1992: An ecological study of the parasitic nematode Hysterothylacium haze in the Japanese common goby Acanthogobius flavimanus, in a brackish inlet. In: R.S. Svrjcek (Ed.), Control of Diseases in Aquaculture: Proceedings of the Nineteenth U.S.-Japan Meeting on Aquaculture. Northwest and Alaska Fisheries Science Centers, Seattle, pp. 63-67.

Yoshinaga T., Ogawa K., Wakabayashi H. 1988: Developmental morphology of Hysterothylacium haze (Nematoda: Anisakidae). Fish Pathol. 23: 19-28.

Yoshinaga T., OGawa K., Wakabayashi H. 1989a: Life cycle of Hysterothylacium haze (Nematoda: Anisakidae: Raphidascaridinae). J. Parasitol. 75: 756-763.

Yoshinaga T., Ogawa K., Wakabayashi H. 1989b: Morphology of the excretory system of Hysterothylacium haze (Nematoda: Anisakidae: Raphidascaridinae). J. Parasitol. 75: 812-814.

ZHUKOV E.V. 1960: [Endoparasitic worms of fishes from the Japan Sea and the South-Kurile shallow waters.] Tr. Zool. Inst. AN SSSR 28: 3-146. (In Russian with English summary.) 